Research Article

\title{
The Analytical Approach to Evaluate the Load-Displacement Relationship of Rock Bolts
}

\author{
Jianhang Chen, ${ }^{1}$ Shengli Yang, ${ }^{1}$ Hongbao Zhao $\mathbb{D}^{1},{ }^{1}$ Junwen Zhang $\mathbb{D},{ }^{1}$ Fulian He, ${ }^{1,2}$ \\ and Shuaifeng Yin $\mathbb{1 0}^{3}$ \\ ${ }^{1}$ School of Energy and Mining Engineering, China University of Mining and Technology (Beijing), Beijing 100083, China \\ ${ }^{2}$ Beijing Key Laboratory for Precise Mining of Intergrown Energy and Resources, \\ China University of Mining and Technology (Beijing), Beijing 100083, China \\ ${ }^{3}$ School of Safety Engineering, North China Institute of Science and Technology, Beijing 101601, China
}

Correspondence should be addressed to Shuaifeng Yin; yinshuaifeng@126.com

Received 16 June 2019; Revised 22 August 2019; Accepted 27 August 2019; Published 28 November 2019

Academic Editor: Robert Černý

Copyright (C) 2019 Jianhang Chen et al. This is an open access article distributed under the Creative Commons Attribution License, which permits unrestricted use, distribution, and reproduction in any medium, provided the original work is properly cited.

Fully grouted rock bolts are widely used in civil engineering and mining engineering, playing a significant role in keeping the stability and safety of excavations. In this paper, the load transfer mechanism of fully grouted rock bolts was studied with an analytical model. A trilinear model was used to depict the bond-slip behaviour of the bolt/grout interface. The displacement of the confining medium was involved in this analytical model. Then, the shear stress propagation along the bolt/grout interface was analysed in the elastic, elastic-softening, elastic-softening-debonding, softening-debonding, and debonding stages. Experimental pull-out tests were used to validate this analytical model. There was a good correlation between experimental and analytical results. A parametric study was conducted to evaluate the influence of Young's modulus of the confining medium, the shear strength of the bolt/grout interface, and the residual shear strength of the bolt/grout interface on the load transfer performance of rock bolts. The results show that increasing Young's modulus of the confining medium was beneficial for improving the load transfer performance of rock bolts. However, once Young's modulus of the confining medium was beyond a critical limit, it had marginal effect on the peak load of rock bolts. Furthermore, increasing the shear strength of the bolt/grout interface and the residual shear strength of the bolt/grout interface led to rising of the peak load of rock bolts. However, compared with the residual shear strength of the bolt/grout interface, increasing the shear strength of the bolt/grout interface had more apparent effect in improving the peak load of rock bolts.

\section{Introduction}

A rock bolt is a rock tendon which can be either a rod or a strand, installed in a borehole to reinforce the surrounding rock mass and soil [1]. Rock bolts have been used in civil and mining for a long time [2]. Numerous field applications and computer simulation have proved that rock bolts play a significant role in improving the internal strength of rock mass and enhancing the safety of underground excavations [3-6].

The rock bolt reinforcement system is basically composed of four components: the surrounding confining medium, e.g., rocks or soils, the rock reinforcement element, the internal fixture, and the external fixture [7-9]. It is found that all these four components have an influence on the performance of a reinforcement system.

To better understand the performance of the reinforcement system, Thompson et al. [10] classified the rock reinforcement system as three types: continuously mechanically coupled (CMC), continuously frictionally coupled (CFC), and discrete mechanically or frictionally coupled (DMFC). This study deals with fully grouted rock bolts, and based on this classification, fully grouted rock bolts belong to the CMC system.

For the CMC system, cementitious grout or polyester resin can be used to bond rock bolts with the surrounding confining medium [11-13]. Via the bonding material, the load from exterior unstable rock mass can be transferred to 
interior stable rock mass. It should be mentioned that in the in situ applications, rock bolts can encounter axial, shear, and combined axial and shear loading conditions [14]. However, this paper focused on the axial performance of rock bolts.

Failure of the rock bolting system has different modes. Jeremic and Delaire [15] summarised that failure of the rock bolting system can be classified as bond failure of the bolt/ grout interface, bond failure of the grout/rock interface, failure of the grout annulus, and failure in the surrounding rock mass. Then, Hutchinson and Diederichs [16] added that rupture of the rock tendon also occurred in the in situ scenario. Nevertheless, among these failure modes, bond failure of the bolt/grout interface and the grout/rock interface are more common to encounter [17].

Jalalifar [18] stated that when fully grouted rock bolts were loaded axially, the shear stress along the bolt/grout interface was larger than the shear stress along the grout/ rock interface because the bolt/grout interface had a smaller contact area. When the grout and the rock had similar strength, failure was likely to occur along the bolt/grout interface. Previous experimental pull-out tests also showed that bond failure of the bolt/grout interface occurred in the tests $[19,20]$. Therefore, this paper deals with the bond failure of the bolt/grout interface.

Gambarova [21] stated that the bonding performance of the bolt/grout interface mainly relies on chemical adhesion, mechanical interlock, and friction. Chemical adhesion plays a negligible role on the bonding performance and can be easily removed after a small relative movement between the bolt and grout [22].

To understand the load transfer performance of rock bolts, extensive research has been conducted via experimental pull-out tests [23-25]. Compared with that, much less work has been conducted with analytical modelling. Hawkes and Evans [26] conducted the pioneering work in analytically modelling the load transfer of rock bolts. Specifically, an analytical model was proposed to evaluate the load distribution along a fully grouted rock bolt. However, this assumption was only valid in the coupling stage. In the modelling process, a linear relationship between the axial stress in the bolt and the shear stress along the bolt/grout interface was assumed. However, this assumption was credible when the bolt was fully coupled with the surrounding medium. With the axial load in the bolt increasing, debonding occurred along the bolt surface, and this assumption may not be valid again. Farmer [27] deduced an analytical model to study the load distribution along a rock bolt. In this analytical model, it was assumed that the shear stress along the bolt/grout interface was linear with the grout shear modulus. Therefore, this model was only applicable when the bolt/grout interface underwent elastic behaviour. Once debonding occurred along the bolt/grout interface, the credibility of this analytical model decreased. Aydan et al. [28] deduced an analytical solution to study the load transfer of rock bolts. However, no experimental work was conducted to validate the credibility of the model. Rajaie [29] studied the load transfer of cable bolts, and an energy approach was adopted to analyse the loading process of cable bolts. There was a good correlation between laboratory results and analytical results. However, this model mainly focused on the peak load calculation, and no equation was deduced to calculate the load variation with displacement in the pull-out process. Therefore, this model cannot be used to study the load-displacement relationship of cable bolts.

Yazici and Kaiser [30] proposed a bond strength model to study the load transfer of plain cable bolts. Later, this model was modified to study the influence of stress change on load transfer of cable bolts [31]. This model treated the bolt/grout interface as a zigzag geometry, similar to a rock joint. For the rock joint, strength of the rock is usually weak along two sides. However, for the cable bolting system, strength of the steel is much higher along the bolt side. Following that, Hyett et al. [32] developed a constitutive model to study the load-displacement performance of cable bolts. Two different boundary conditions were considered: constant normal stress and constant normal stiffness. This model assumed that the shear stress along the bolt/grout interface was uniform. However, experimental work proved that when the bolt had a long embedment length, the shear stress along the bolt/grout interface was not uniform [22]. Therefore, this model was applicable to calculate the loaddisplacement relationship for short embedded bolts. However, it may not be suitable for long embedded bolts. A load distribution model was proposed by Hyett et al. [33]. This model can be used to study the load distribution in the embedment section and the anchor section. Moosavi [34] developed an analytical model for modified cable bolts. However, when modified cable bolts were used to reinforce rock masses, the modified geometry can be installed at different positions in the embedment section. And, the influence of the modified geometry position on the load transfer performance of cable bolts was not considered. $\mathrm{Li}$ and Stillborg [35] developed an analytical model to study the load distribution of rock bolts. The bolt/grout interface was assumed to be composed of four sections: completely decoupled, partially decoupled, softening, and elastic.

Cai et al. [36] used a modified shear-lag model to study the load transfer of rock bolts. However, the softening behaviour of the bolt/grout interface was neglected. Xiao and Chen [37] assumed that the bolt/grout interface underwent elastic, softening, and debonding stages and developed a model for rock bolts. Ren et al. [38] deduced the load transfer process of rock bolts with an analytical model. Experimental work was used to validate the credibility of this analytical model. However, when deducing the analytical model, it was assumed that the shear slippage of the bolt/grout interface was equal to the axial displacement of the rock bolt. Then, the displacement of the surrounding confining medium was neglected. Consequently, this model cannot be used to study the influence of the surrounding confining medium on the performance of rock bolts. Blanco Martín et al. [39] proposed an analytical solution to evaluate the load-displacement performance of rock bolts. Jalalifar [40] evaluated the performance of rock bolts installed in an elasto-plastic rock mass. In this model, it was assumed that the shear force in the grout annulus had a linear relationship with the shear slippage. Therefore, this model was only valid when the bolt/ 
grout interface underwent elastic deformation. After the bolt/grout interface started plastic deformation, this model was not valid again. Cao et al. [41] studied the influence of rib geometry on the bonding capacity of rock bolts. It was predicted that rock bolts with small rib face angles were more effective in hard rock conditions.

Ma et al. [42] used a nonlinear equation to depict the bond-slip behaviour of the bolt/grout interface and studied the load transfer of rock bolts. Later, the model was modified to study the influence of free end slip on the performance of rock bolts [43]. However, in this model, an empirical equation was used to depict the bond-slip relationship of the bolt/grout interface. Therefore, the properties of the rock bolting system may modify the coefficients in the bond-slip model. Consequently, this model cannot be used to predict the influence of rock mass confinement on the performance of rock bolts. Chen et al. [13] used an analytical model to study the axial performance of cable bolts. However, the model was only appropriate for laboratory pull-out scenario. Li et al. [44] developed an analytical model to study the load transfer of modified cable bolts. Cable bolts with short embedment length were used to validate the model. However, in situ tests proved that the installed cable bolts can be very long for the field scenario [45]. And, whether this model can be used to study the performance of cable bolts with long embedment length was not discussed.

The literature review shows that for the rock bolting system, when the shear behaviour of the bolt/grout interface was depicted with a bond-slip equation, different analytical models can be used, such as the exponential model [42] or the trilinear model [46]. Among them, the trilinear model considers the elastic, softening, and debonding behaviour of the bolt/grout interface and thus is more commonly used. However, when the trilinear model was incorporated into the rock bolting system to deduce the load-displacement relationship of rock bolts, the involvement of the surrounding confining medium was usually not considered.

It should be mentioned that Vaculik et al. [47] conducted an analytical study to evaluate the load-slip relationship of the FRP-to-substrate joints with the bond-slip model. A framework was proposed to depict the performance of FRPto-substrate joints. However, for the rock bolting system, cylindrical rock bolts are always used to reinforce the excavated rock masses, such as tunnels, roadways, and stopes $[48,49]$. Therefore, this paper applies the method proposed by Vaculik et al. [47] into the fully grouted rock bolting system and further deduced the specific analytical solution for fully grouted rock bolts. Additionally, they evaluated the performance of FRP-to-substrate joints with the embedment length ranging from short to long. However, for fully grouted rock bolts, the embedment length is usually extremely long [45, 50]. For example, Cao et al. [51] summarised that the embedment length for a rock bolt can be around $3 \mathrm{~m}$. Furthermore, when the cable bolt is used, the embedment length may range from $3 \mathrm{~m}$ to $15 \mathrm{~m}$. Considering this, this paper especially focused on the long embedment length scenario for rock bolts.

First, the relationship between the shear stress of the bolt/grout interface and the shear slippage was simulated with a trilinear model. Then, the pull-out process of rock bolts was analysed with five stages: elastic, elastic-softening, elastic-softening-debonding, softening-debonding, and debonding stages. After that, the analytical model was validated with experimental pull-out tests. Finally, a parametric study was conducted to evaluate the influence of Young's modulus of the confining medium, the shear strength of the bolt/grout interface, and the residual shear strength of the bolt/grout interface on the load transfer performance of rock bolts.

\section{Analytical Modelling}

2.1. Bond-Slip Model. A trilinear model was used to depict the bond-slip behaviour of the bolt/grout interface. The trilinear model is composed of three parts: ascending section, descending section, and horizontal section [13, 38, 47], as shown in Figure 1. Specifically, with the shear slippage of the bolt/grout interface increasing from 0 to $\delta_{p}$, the shear stress increases linearly from zero to the shear strength of the bolt/grout interface. Then, with $\delta$ increasing to $\delta_{r}$, the shear stress decreases linearly to the residual shear strength of the bolt/grout interface. After $\delta_{r}$, the shear stress remains constant and equals $\tau_{r}$.

Therefore, the trilinear model can be expressed as $[13,38]$

$$
\begin{aligned}
& \tau=\frac{\tau_{p}}{\delta_{p}} \delta, \quad 0 \leq \delta \leq \delta_{p}, \\
& \tau=\frac{\tau_{p} \delta_{r}-\tau_{r} \delta_{p}}{\delta_{r}-\delta_{p}}-\frac{\tau_{p}-\tau_{r}}{\delta_{r}-\delta_{p}} \delta, \quad \delta_{p}<\delta \leq \delta_{r}, \\
& \tau=\tau_{r}, \quad \delta>\delta_{r},
\end{aligned}
$$

where $\tau$ is the shear stress of the bolt/grout interface, $\mathrm{Pa}$; $\tau_{p}$ is the shear strength of the bolt/grout interface, $\mathrm{Pa} ; \delta_{p}$ is the shear slippage when the shear strength of the bolt/grout interface reaches, $\mathrm{m} ; \tau_{r}$ is the residual shear strength of the bolt/grout interface, $\mathrm{Pa}$; and $\delta_{r}$ is the shear slippage when the residual shear strength of the bolt/grout interface reaches, $\mathrm{m}$.

2.2. Governing Equation. In previous research, the shear slippage of the bolt/grout interface was usually simplified as the axial displacement of the rock bolt [38, 42]. However, previous experimental work proved that the shear slippage of the bolt/grout interface was different from the axial displacement of the rock bolt because of the displacement of the confining medium [52]. Furthermore, Hyett et al. [33] found that the displacement of the confining medium had an apparent influence on the load transfer performance of rock bolts. Therefore, neglecting the displacement of the confining medium in the analytical model could not properly reflect the load transfer performance of rock bolts. Considering this issue, in this paper, the displacement of the confining medium was included.

Since this study aims at studying the bond failure of the bolt/grout interface, the grout/medium interface was assumed to be intact in the pull-out process of rock bolts. Then, 


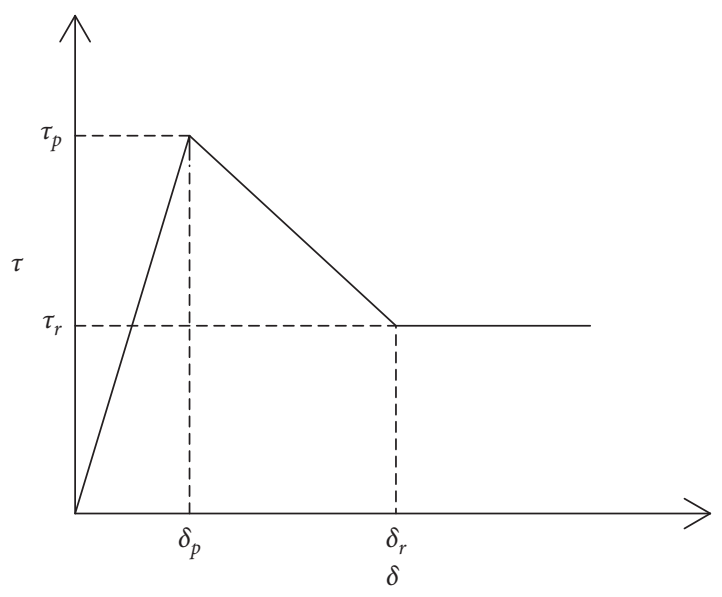

Figure 1: A trilinear model [13, 38, 47].

the shear slippage of the bolt/grout interface was defined as the relative movement between the rock bolt and the confining medium $[53,54]$ :

$$
\delta(x)=u_{b}(x)-u_{m}(x),
$$

where $\delta(x)$ is the shear slippage of the bolt/grout interface at the position of $x, \mathrm{~m} ; u_{b}(x)$ is the rock bolt displacement at the position of $x, \mathrm{~m}$; and $u_{m}(x)$ is the confining medium displacement at the position of $x, \mathrm{~m}$. leads to

Differentiating equation (2) twice with respect to $x$

$$
\frac{\mathrm{d}^{2} \delta(x)}{\mathrm{d} x^{2}}=\frac{\mathrm{d}^{2} u_{b}(x)}{\mathrm{d} x^{2}}-\frac{\mathrm{d}^{2} u_{m}(x)}{\mathrm{d} x^{2}} .
$$

The axial stress in the rock bolt can be expressed with the displacement of the rock bolt. As for the confining medium, this is also applicable. Then, the following equations can be acquired [40]:

$$
\begin{gathered}
\sigma_{b}(x)=E_{b} \frac{\mathrm{d} u_{b}(x)}{\mathrm{d} x}, \\
\sigma_{m}(x)=E_{m} \frac{\mathrm{d} u_{m}(x)}{\mathrm{d} x},
\end{gathered}
$$

where $E_{b}$ is Young's modulus of the rock bolt, $\mathrm{Pa} ; \sigma_{b}(x)$ is the axial stress in the rock bolt at the position of $x, \mathrm{~Pa} ; E_{m}$ is Young's modulus of the confining medium, $\mathrm{Pa}$; and $\sigma_{m}(x)$ is the axial stress applied on the confining medium, $\mathrm{Pa}$.

Substituting equations (4) and (5) into (3) leads to

$$
\frac{\mathrm{d}^{2} \delta(x)}{\mathrm{d} x^{2}}=\frac{1}{E_{b}} \frac{\mathrm{d} \sigma_{b}(x)}{\mathrm{d} x}-\frac{1}{E_{m}} \frac{\mathrm{d} \sigma_{m}(x)}{\mathrm{d} x} .
$$

According to the mechanical equilibrium, the relationship between the axial stress in the bolt and the axial stress applied on the confining medium can be expressed as [55]

$$
\sigma_{m}=-\sigma_{b} \frac{\pi r_{b}^{2}}{A_{m}}
$$

where $A_{m}$ is the cross-sectional area of the confining medium, $\mathrm{m}^{2}$ and $r_{b}$ is the rock bolt radius, $\mathrm{m}$.

Substituting equation (7) into equation (6) leads to

$$
\frac{\mathrm{d}^{2} \delta(x)}{\mathrm{d} x^{2}}=\left(\frac{1}{E_{b}}+\frac{\pi r_{b}^{2}}{E_{m} A_{m}}\right) \frac{\mathrm{d} \sigma_{b}(x)}{\mathrm{d} x} .
$$

The relationship between the axial stress in the rock bolt and the shear stress along the bolt/grout interface can be seen in Figure 2.

Then, the following equation can be acquired [42]:

$$
\tau(x)=\frac{r_{b}}{2} \frac{\mathrm{d} \sigma_{b}(x)}{\mathrm{d} x}
$$

where $\tau(x)$ is the shear stress of the bolt/grout interface at the position of $x, \mathrm{~Pa}$.

Substituting equation (9) into equation (8) leads to

$$
\frac{\mathrm{d}^{2} \delta(x)}{\mathrm{d} x^{2}}-\frac{2}{r_{b}}\left(\frac{1}{E_{b}}+\frac{\pi r_{b}^{2}}{E_{m} A_{m}}\right) \tau(x)=0 .
$$

It is defined that

$$
\lambda^{2}=\frac{2}{r_{b}}\left(\frac{1}{E_{b}}+\frac{\pi r_{b}^{2}}{E_{m} A_{m}}\right) .
$$

Then, equation (10) can be written as

$$
\frac{\mathrm{d}^{2} \delta(x)}{\mathrm{d} x^{2}}-\lambda^{2} \tau(x)=0 .
$$

Equation (12) is the governing equation of this analytical model, and it can be solved with the predefined shear stress equations.

2.3. Pull-Out Stages of Rock Bolts. According to previous research, the pull-out stages of the bolt/grout interface can be classified as the elastic stage, elastic-softening stage, elastic-softening-debonding stage, softening-debonding stage, and debonding stage $[38,53,56]$. Therefore, in the following contents, the pull-out process of a rock bolt was analysed with those five stages.

2.3.1. Elastic Stage. When the pull-out load is small, the bolt/ grout interface undergoes elastic deformation. And, the full bolt/grout interface is elastic, as shown in Figure 3.

Then, equation (1a) can be substituted into equation (12), leading to

$$
\frac{\mathrm{d}^{2} \delta(x)}{\mathrm{d} x^{2}}-\frac{\tau_{p}}{\delta_{p}} \lambda^{2} \delta(x)=0 .
$$

It is defined that

$$
\lambda_{1}^{2}=\frac{\tau_{p}}{\delta_{p}} \lambda^{2}
$$

Then, equation (13) can be written as

$$
\frac{\mathrm{d}^{2} \delta(x)}{\mathrm{d} x^{2}}-\lambda_{1}^{2} \delta(x)=0 .
$$

Equation (15) can be solved with boundary conditions. First, the axial stress in the bolt should be deduced. According to equation (2), the following equation can be acquired: 


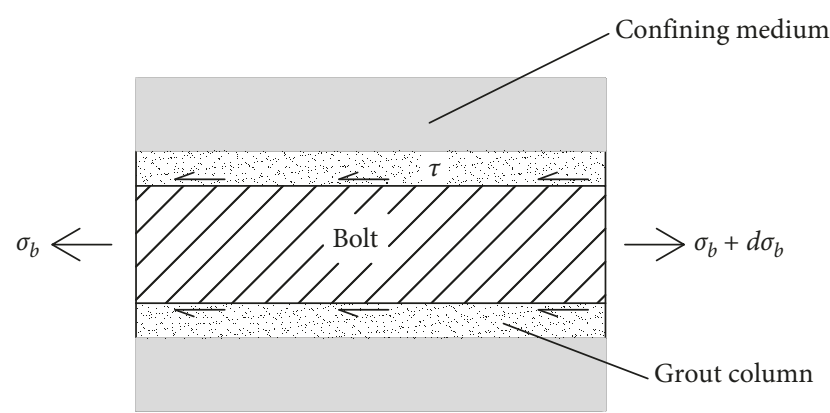

FIGURE 2: Cross section view of a rock bolting system.

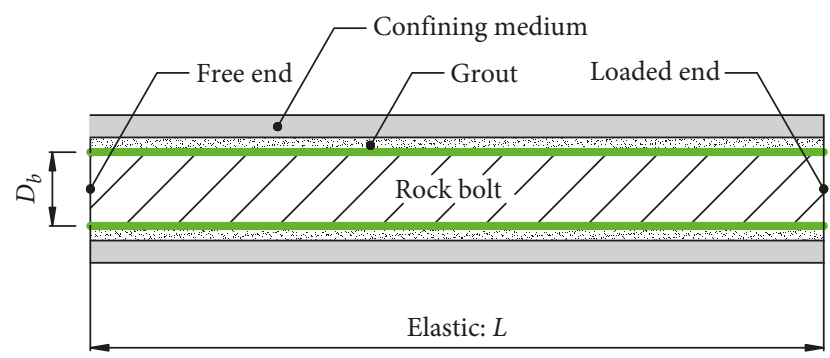

Figure 3: The full bolt/grout interface is elastic in the elastic stage where $D_{b}$ is the diameter of the rock bolt, $\mathrm{m}$.

$$
\frac{\mathrm{d} \delta(x)}{\mathrm{d} x}=\frac{\mathrm{d} u_{b}(x)}{\mathrm{d} x}-\frac{\mathrm{d} u_{m}(x)}{\mathrm{d} x} .
$$

It can be further written as

$$
\frac{\mathrm{d} \delta(x)}{\mathrm{d} x}=\frac{\sigma_{b}(x)}{E_{b}}-\frac{\sigma_{m}(x)}{E_{m}} .
$$

Substituting equation (7) into equation (17) leads to

$$
\frac{\mathrm{d} \delta(x)}{\mathrm{d} x}=\left(\frac{1}{E_{b}}+\frac{\pi r_{b}^{2}}{E_{m} A_{m}}\right) \sigma_{b}(x) .
$$

Substituting equation (11) into equation (18), the axial stress in the bolt can be written as

$$
\sigma_{b}(x)=\frac{2}{r_{b} \lambda^{2}} \frac{\mathrm{d} \delta(x)}{\mathrm{d} x} .
$$

The boundary conditions are

$$
\begin{aligned}
& \sigma_{b}(x=0)=0, \\
& \sigma_{b}(x=L)=\frac{F}{\pi r_{b}^{2}},
\end{aligned}
$$

where $F$ is the pull-out load of the rock bolt, N.

Combining equations (19)-(21) with equation (15) leads to

$$
\begin{gathered}
\delta(x)=\frac{F \lambda_{1} \delta_{p}}{2 \pi r_{b} \tau_{p} \sinh \left(\lambda_{1} L\right)} \cosh \left(\lambda_{1} x\right), \\
\sigma_{b}(x)=\frac{F}{\pi r_{b}^{2} \sinh \left(\lambda_{1} L\right)} \sinh \left(\lambda_{1} x\right),
\end{gathered}
$$

$$
\tau(x)=\frac{F \lambda_{1}}{2 \pi r_{b} \sinh \left(\lambda_{1} L\right)} \cosh \left(\lambda_{1} x\right) .
$$

It is defined that at the loaded end, the shear slippage of the bolt/grout interface is equal to the pull-out displacement of the rock bolt [57]. Substituting $x=L$ into equation (22), the pull-out load of the rock bolt can be expressed as

$$
F=\frac{2 \pi r_{b} \tau_{p} \tanh \left(\lambda_{1} L\right)}{\lambda_{1} \delta_{p}} u_{b}
$$

where $u_{b}$ is the pull-out displacement of the rock bolt, $\mathrm{m}$.

At the end of this stage, the shear stress at the position of $x=L$ increases to the shear strength of the bolt/grout interface. Therefore, substituting $\tau(x=L)=\tau_{p}$ into equation (24) leads to

$$
F_{\text {sof }}=\frac{2 \pi r_{b} \tau_{p} \tanh \left(\lambda_{1} L\right)}{\lambda_{1}}
$$

where $F_{\text {sof }}$ is the pull-out load when the bolt/grout interface starts softening, $\mathrm{N}$.

2.3.2. Elastic-Softening Stage. In the elastic-softening stage, the full bolt/grout interface is composed of the elastic section and softening section, as shown in Figure 4.

It is defined that $a_{s}$ is the softening length. In the elasticsoftening stage, the interface in the domain $\left[0, L-a_{s}\right]$ is still elastic. One boundary condition is equation (20) and the other boundary condition is

$$
\tau\left(x=L-a_{s}\right)=\tau_{p} .
$$

Combining equations (9), (19), (20), and (27) with equation (15) leads to

$$
\begin{aligned}
\delta(x) & =\frac{\delta_{p}}{\cosh \left(\lambda_{1}\left(L-a_{s}\right)\right)} \cosh \left(\lambda_{1} x\right), \\
\sigma_{b}(x) & =\frac{2 \tau_{p}}{r_{b} \lambda_{1} \cosh \left(\lambda_{1}\left(L-a_{s}\right)\right)} \sinh \left(\lambda_{1} x\right), \\
\tau(x) & =\frac{\tau_{p}}{\cosh \left(\lambda_{1}\left(L-a_{s}\right)\right)} \cosh \left(\lambda_{1} x\right) .
\end{aligned}
$$

Substituting $x=L-a_{s}$ into equation (29), the axial stress can be acquired:

$$
\sigma_{b}\left(x=L-a_{s}\right)=\frac{2 \tau_{p}}{r_{b} \lambda_{1}} \tanh \left(\lambda_{1}\left(L-a_{s}\right)\right) .
$$

In the domain $\left[L-a_{s}, L\right]$, the bolt/grout interface softens. Substituting equation (1b) into equation (12) leads to

$$
\frac{\mathrm{d}^{2} \delta(x)}{\mathrm{d} x^{2}}+\lambda^{2} \frac{\tau_{p}-\tau_{r}}{\delta_{r}-\delta_{p}} \delta(x)-\lambda^{2} \frac{\tau_{p} \delta_{r}-\tau_{r} \delta_{p}}{\delta_{r}-\delta_{p}}=0 .
$$

It is defined that

$$
\lambda_{2}^{2}=\frac{\tau_{p}-\tau_{r}}{\delta_{r}-\delta_{p}} \lambda^{2}
$$




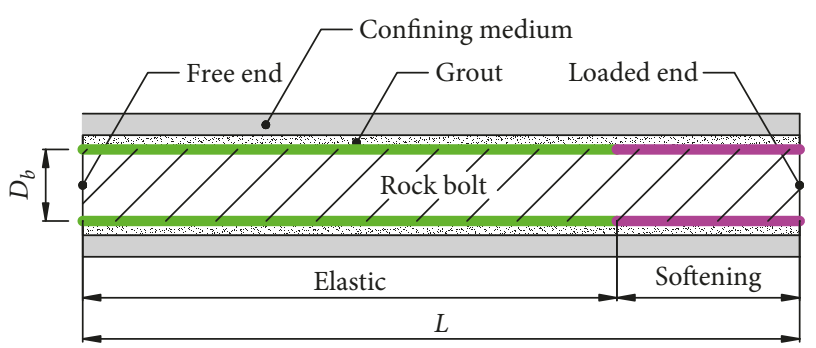

FIGURE 4: The full bolt/grout interface is composed of the elastic section and softening section in the elastic-softening stage.

Therefore, equation (32) can be further written as

$$
\frac{\mathrm{d}^{2} \delta(x)}{\mathrm{d} x^{2}}+\lambda_{2}^{2} \delta(x)-\lambda_{2}^{2} \frac{\tau_{p} \delta_{r}-\tau_{r} \delta_{p}}{\tau_{p}-\tau_{r}}=0 .
$$

The boundary conditions are equations (27) and (31). Combining equations (9), (19), (27), and (31) with equation (34) leads to

$$
\begin{aligned}
\delta(x)= & \frac{\lambda_{1} \delta_{p}}{\lambda_{2}} \tanh \left(\lambda_{1}\left(L-a_{s}\right)\right) \sin \left(\lambda_{2}\left(x+a_{s}-L\right)\right) \\
& -\frac{\lambda_{1}^{2} \delta_{p}}{\lambda_{2}^{2}} \cos \left(\lambda_{2}\left(L-a_{s}-x\right)\right)+\frac{\tau_{p} \delta_{r}-\tau_{r} \delta_{p}}{\tau_{p}-\tau_{r}}, \\
\sigma_{b}(x)= & \frac{2 \tau_{p}}{r_{b}}\left(\frac{1}{\lambda_{1}} \tanh \left(\lambda_{1}\left(L-a_{s}\right)\right) \cos \left(\lambda_{2}\left(L-a_{s}-x\right)\right)\right. \\
& \left.+\frac{1}{\lambda_{2}} \sin \left(\lambda_{2}\left(x+a_{s}-L\right)\right)\right), \\
\tau(x)= & \tau_{p}\left(\frac{\lambda_{2}}{\lambda_{1}} \tanh \left(\lambda_{1}\left(L-a_{s}\right)\right) \sin \left(\lambda_{2}\left(L-a_{s}-x\right)\right)\right. \\
& \left.+\cos \left(\lambda_{2}\left(L-a_{s}-x\right)\right)\right) .
\end{aligned}
$$

Substituting $x=L$ and $\sigma_{b}(x=L)=F / \pi r_{b}^{2}$ into equations (35) and (36), respectively, the pull-out displacement and pull-out load of the rock bolt can be acquired:

$$
F=2 \pi r_{b} \tau_{p}\left(\frac{1}{\lambda_{1}} \tanh \left(\lambda_{1}\left(L-a_{s}\right)\right) \cos \left(\lambda_{2} a_{s}\right)+\frac{1}{\lambda_{2}} \sin \left(\lambda_{2} a_{s}\right)\right),
$$

$$
\begin{aligned}
u_{b}= & \frac{\lambda_{1} \delta_{p}}{\lambda_{2}} \tanh \left(\lambda_{1}\left(L-a_{s}\right)\right) \sin \left(\lambda_{2} a_{s}\right)-\frac{\lambda_{1}^{2} \delta_{p}}{\lambda_{2}^{2}} \cos \left(\lambda_{2} a_{s}\right) \\
& +\frac{\tau_{p} \delta_{r}-\tau_{r} \delta_{p}}{\tau_{p}-\tau_{r}} .
\end{aligned}
$$

At the end of this stage, the shear stress at the position of $x=L$ reduces to $\tau_{r}$. Therefore, substituting $\tau(x=L)=\tau_{r}$ into equation (37) leads to

$$
\cos \left(\lambda_{2} a_{s}\right)-\frac{\lambda_{2}}{\lambda_{1}} \tanh \left(\lambda_{1}\left(L-a_{s}\right)\right) \sin \left(\lambda_{2} a_{s}\right)=\frac{\tau_{r}}{\tau_{p}} .
$$

For an infinite embedment length, $\tanh \left(\lambda_{1}\left(L-a_{s}\right)\right)$ is equal to 1 . Then, the softening length when the elasticsoftening stage ends can be acquired:

$$
a_{s 1}=\frac{1}{\lambda_{2}}\left(\arcsin \frac{\lambda_{1}}{\sqrt{\lambda_{1}^{2}+\lambda_{2}^{2}}}-\arcsin \frac{\tau_{r} \lambda_{1}}{\tau_{p} \sqrt{\lambda_{1}^{2}+\lambda_{2}^{2}}}\right),
$$

where $a_{s 1}$ is the softening length when the elastic-softening stage ends, $\mathrm{m}$.

2.3.3. Elastic-Softening-Debonding Stage. After $\tau(x=L)$ reduces to $\tau_{r}$, the bolt/grout interface enters the elastic-softening-debonding stage. In this stage, the full bolt/grout interface is composed of elastic section, softening section, and debonding section, as shown in Figure 5.

Assuming that the debonding length is $a_{d}$, the bolt/grout interface in the domain $\left[0, L-a_{d}-a_{s}\right]$ is still elastic. Therefore, equations (28)-(30) are still valid if $L$ is replaced with $L-a_{d}$ :

$$
\begin{gathered}
\delta(x)=\frac{\delta_{1}}{\cosh \left(\lambda_{1}\left(L-a_{d}-a_{s}\right)\right)} \cosh \left(\lambda_{1} x\right), \\
\sigma_{b}(x)=\frac{2 \tau_{p}}{r_{b} \lambda_{1} \cosh \left(\lambda_{1}\left(L-a_{d}-a_{s}\right)\right)} \sinh \left(\lambda_{1} x\right), \\
\tau(x)=\frac{\tau_{p}}{\cosh \left(\lambda_{1}\left(L-a_{d}-a_{s}\right)\right)} \cosh \left(\lambda_{1} x\right) .
\end{gathered}
$$

As for the domain $\left[L-a_{d}-a_{s}, L-a_{d}\right]$, the bolt/grout interface softens. Therefore, equations (35)-(37) are still valid if $L$ is replaced with $\left(L-a_{d}\right)$ :

$$
\begin{aligned}
\delta(x)= & \frac{\lambda_{1} \delta_{p}}{\lambda_{2}} \tanh \left(\lambda_{1}\left(L-a_{d}-a_{s}\right)\right) \sin \left(\lambda_{2}\left(x+a_{d}+a_{s}-L\right)\right) \\
& -\frac{\lambda_{1}^{2} \delta_{p}}{\lambda_{2}^{2}} \cos \left(\lambda_{2}\left(L-a_{d}-a_{s}-x\right)\right)+\frac{\tau_{p} \delta_{r}-\tau_{r} \delta_{p}}{\tau_{p}-\tau_{r}},
\end{aligned}
$$

$$
\begin{aligned}
\sigma_{b}(x)= & \frac{2 \tau_{p}}{r_{b}}\left(\frac{1}{\lambda_{1}} \tanh \left(\lambda_{1}\left(L-a_{d}-a_{s}\right)\right) \cos \right. \\
& \cdot\left(\lambda_{2}\left(L-a_{d}-a_{s}-x\right)\right) \\
& \left.+\frac{1}{\lambda_{2}} \sin \left(\lambda_{2}\left(x+a_{d}+a_{s}-L\right)\right)\right), \\
\tau(x)= & \tau_{p}\left(\frac{\lambda_{2}}{\lambda_{1}} \tanh \left(\lambda_{1}\left(L-a_{d}-a_{s}\right)\right) \sin \right. \\
& \cdot\left(\lambda_{2}\left(L-a_{d}-a_{s}-x\right)\right) \\
& \left.+\cos \left(\lambda_{2}\left(L-a_{d}-a_{s}-x\right)\right)\right) .
\end{aligned}
$$




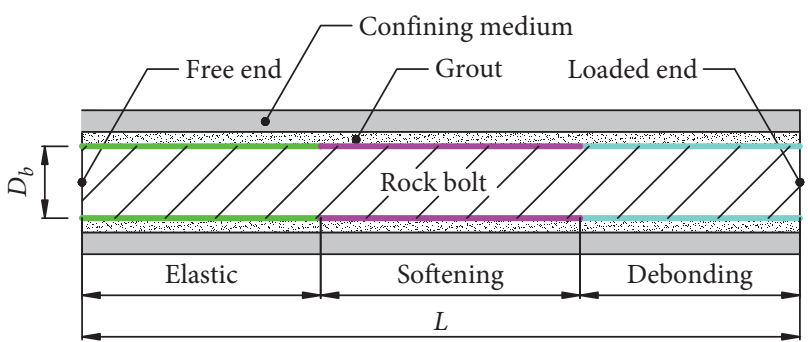

Figure 5: The full bolt/grout interface is composed of the elastic section, softening section, and debonding section in the elasticsoftening-debonding stage.

Substituting $\tau\left(L-a_{d}\right)=\tau_{r}$ into equation (47) leads to

$$
\cos \left(\lambda_{2} a_{s}\right)-\frac{\lambda_{2}}{\lambda_{1}} \tanh \left(\lambda_{1}\left(L-a_{d}-a_{s}\right)\right) \sin \left(\lambda_{2} a_{s}\right)-\frac{\tau_{r}}{\tau_{p}}=0 .
$$

Equation (48) depicts the relationship between $a_{d}$ and $a_{s}$. It shows that in this stage, the softening length keeps varying with the debonding length increasing. Combining equations (45) and (48) together, the shear slippage of the bolt/grout interface at the position of $x=L-a_{d}$ can be acquired:

$$
\delta\left(x=L-a_{d}\right)=\delta_{r} .
$$

Substituting $x=L-a_{d}$ into equation (46), the axial stress can be acquired:

$$
\begin{aligned}
\sigma_{b}\left(x=L-a_{d}\right)= & \frac{2 \tau_{p}}{r_{b}}\left(\frac{1}{\lambda_{1}} \tanh \left(\lambda_{1}\left(L-a_{d}-a_{s}\right)\right) \cos \left(\lambda_{2} a_{s}\right)\right. \\
& \left.+\frac{1}{\lambda_{2}} \sin \left(\lambda_{2} a_{s}\right)\right) .
\end{aligned}
$$

For the domain $\left[L-a_{d}, L\right]$, the bolt/grout interface debonds and the shear stress equals $\tau_{r}$ :

$$
\tau(x)=\tau_{r} .
$$

Also, equation (1c) can be substituted to equation (12), leading to

$$
\frac{\mathrm{d}^{2} \delta(x)}{\mathrm{d} x^{2}}=\lambda^{2} \tau_{r}
$$

Substituting equations (19), (49), and (50) into equation (52) leads to

$$
\begin{aligned}
\delta(x)= & \delta_{r}+\frac{1}{2} \lambda^{2} \tau_{r}\left(x^{2}-\left(L-a_{d}\right)^{2}\right)+\left(\frac{\tau_{p} \lambda^{2}}{\lambda_{1}} \tanh \right. \\
& \cdot\left(\lambda_{1}\left(L-a_{d}-a_{s}\right)\right) \cos \left(\lambda_{2} a_{s}\right) \\
& \left.+\frac{\tau_{p} \lambda^{2}}{\lambda_{2}} \sin \left(\lambda_{2} a_{s}\right)-\lambda^{2} \tau_{r}\left(L-a_{d}\right)\right)\left(x+a_{d}-L\right),
\end{aligned}
$$

$$
\begin{aligned}
\sigma_{b}(x)= & \frac{2 \tau_{p}}{r_{b}}\left(\frac{1}{\lambda_{1}} \tanh \left(\lambda_{1}\left(L-a_{d}-a_{s}\right)\right)\right. \\
& \left.\cdot \cos \left(\lambda_{2} a_{s}\right)+\frac{1}{\lambda_{2}} \sin \left(\lambda_{2} a_{s}\right)\right)+\frac{2 \tau_{r}}{r_{b}}\left(x+a_{d}-L\right) .
\end{aligned}
$$

Substituting $x=L$ and $\sigma_{b}(x=L)=F / \pi r_{b}^{2}$ into equations (53) and (54), the pull-out displacement and load of the rock bolt can be acquired:

$$
\begin{aligned}
u_{b}= & \delta_{r}+\frac{\lambda^{2} a_{d}^{2} \tau_{r}}{2}+\left(\frac{\tau_{p} \lambda^{2}}{\lambda_{1}} \tanh \left(\lambda_{1}\left(L-a_{d}-a_{s}\right)\right)\right. \\
& \left.\cdot \cos \left(\lambda_{2} a_{s}\right)+\frac{\tau_{p} \lambda^{2}}{\lambda_{2}} \sin \left(\lambda_{2} a_{s}\right)\right) a_{d} \\
F= & 2 \pi r_{b}\left(\frac{\tau_{p}}{\lambda_{1}} \tanh \left(\lambda_{1}\left(L-a_{d}-a_{s}\right)\right)\right. \\
& \left.\cdot \cos \left(\lambda_{2} a_{s}\right)+\frac{\tau_{p}}{\lambda_{2}} \sin \left(\lambda_{2} a_{s}\right)+\tau_{r} a_{d}\right) .
\end{aligned}
$$

The maximum pull-out load occurs in this stage and can be acquired by solving equations (48) and (56) together.

At the end of this stage, the elastic length disappears. Therefore, $L-a_{d}=a_{s}$. Substituting it into equation (48) leads to

$$
a_{s 2}=\frac{1}{\lambda_{2}} \arccos \left(\frac{\tau_{r}}{\tau_{p}}\right),
$$

where $a_{s 2}$ is the softening length when the elastic-softeningdebonding stage ends, $\mathrm{m}$.

2.3.4. Softening-Debonding Stage. After the elastic length disappears, the bolt/grout interface enters the softeningdebonding stage. In the domain $\left[0, L-a_{d}\right]$, the bolt/grout interface softens. Substituting equations (9), (19), and (20) and $\tau\left(x=L-a_{d}\right)=\tau_{r}$ into equation (34) leads to 


$$
\delta(x)=\frac{\tau_{r}\left(\delta_{p}-\delta_{r}\right)}{\left(\tau_{p}-\tau_{r}\right) \cos \left(\lambda_{2}\left(L-a_{d}\right)\right)} \cos \left(\lambda_{2} x\right)+\frac{\tau_{p} \delta_{r}-\tau_{r} \delta_{p}}{\tau_{p}-\tau_{r}},
$$

$\sigma_{b}(x)=\frac{2 \tau_{r}}{r_{b} \lambda_{2} \cos \left(\lambda_{2}\left(L-a_{d}\right)\right)} \sin \left(\lambda_{2} x\right)$,

$$
\tau(x)=\frac{\tau_{r}}{\cos \left(\lambda_{2}\left(L-a_{d}\right)\right)} \cos \left(\lambda_{2} x\right) .
$$

Substituting $x=L-a_{d}$ into equations (58) and (59) leads to

$$
\begin{aligned}
\delta\left(x=L-a_{d}\right) & =\delta_{r}, \\
\sigma_{b}\left(x=L-a_{d}\right) & =\frac{2 \tau_{r}}{r_{b} \lambda_{2}} \tan \left(\lambda_{2}\left(L-a_{d}\right)\right) .
\end{aligned}
$$

For the domain $\left[L-a_{d}, L\right]$, the bolt/grout interface debonds. Substituting equations (19), (61), and (62) into equation (52) leads to

$$
\begin{aligned}
\delta(x)= & \delta_{r}+\frac{\lambda^{2} \tau_{r}}{2}\left(x^{2}-\left(L-a_{d}\right)^{2}\right) \\
& +\left(\frac{\lambda^{2} \tau_{r}}{\lambda_{2}} \tan \left(\lambda_{2}\left(L-a_{d}\right)\right)-\lambda^{2} \tau_{r}\left(L-a_{d}\right)\right) \\
& \cdot\left(x+a_{d}-L\right), \\
\sigma_{b}(x)= & \frac{2 \tau_{r}}{r_{b}}\left(\frac{\tan \left(\lambda_{2}\left(L-a_{d}\right)\right)}{\lambda_{2}}+x+a_{d}-L\right) .
\end{aligned}
$$

Substituting $x=L$ and $\sigma_{b}(x=L)=F / \pi r_{b}^{2}$ into equations (63) and (64), the pull-out displacement and load of the rock bolt can be acquired:

$$
\begin{gathered}
u_{b}=\delta_{r}+\lambda^{2} \tau_{r} a_{d}\left(\frac{a_{d}}{2}+\frac{\tan \left(\lambda_{2}\left(L-a_{d}\right)\right)}{\lambda_{2}}\right), \\
F=2 \pi r_{b} \tau_{r}\left(\frac{\tan \left(\lambda_{2}\left(L-a_{d}\right)\right)}{\lambda_{2}}+a_{d}\right) .
\end{gathered}
$$

At the end of this stage, the debonding length equals the full embedment length. Therefore, substituting $a_{d}=L$ into equations (65) and (66), the pull-out displacement and load of the rock bolt at the end of the softening-debonding stage can be acquired:

$$
\begin{aligned}
& u_{b 0}=\delta_{r}+\frac{\lambda^{2} \tau_{r} L^{2}}{2}, \\
& F_{0}=2 \pi r_{b} \tau_{r} L
\end{aligned}
$$

where $u_{b 0}$ is the pull-out displacement of the rock bolt at the end of the softening-debonding stage, $\mathrm{m}$ and $F_{0}$ is the pullout load of the rock bolt at the end of the softeningdebonding stage, $\mathrm{N}$.
2.3.5. Debonding Stage. After the softening length disappears, the bolt/grout interface enters the debonding stage. Since the full bolt/grout interface undergoes debonding, the relationship between the pull-out load and displacement can be expressed as

$$
F_{0}-F=2 \pi r_{b} \tau_{r}\left(u_{b}-u_{b 0}\right) .
$$

Substituting equations (67) and (68) into equation (69) leads to

$$
F=2 \pi r_{b} \tau_{r}\left(L+\delta_{r}+\frac{\lambda^{2} \tau_{r} L^{2}}{2}-u_{b}\right)
$$

\section{Calibration of the Input Parameters}

In this analytical model, the mechanical properties of the rock bolt and the confining medium, such as $r_{b}, E_{b}$, and $E_{m}$, can be acquired based on the rock bolt pull-out scenario. Specifically, $r_{b}$ and $E_{b}$ can be acquired from the rock bolt specification provided by the bolt manufacturer. $E_{m}$ can be acquired by conducting uniaxial compressive strength tests on samples cored from the confining medium.

As for the mechanical properties of the bond-slip model, they can be calibrated from the experimental load-displacement results. Figure 6 shows a typical load-displacement curve of rock bolts.

In the initial stage of the load-displacement curve, the pull-out load of the rock bolt generally had a linear relationship with the pull-out displacement. Therefore, Point 1 represents the point where the linear relationship of the pullout load and displacement ends in the load-displacement curve. Then, $\delta_{p}$ equals the pull-out displacement at Point 1 . Also, $F_{\text {sof }}$ equals the pull-out load at Point 1 . Substituting $F_{\text {sof }}$ and $\delta_{p}$ into equation (26), $\tau_{p}$ can be acquired.

When the rock bolt reaches the maximum pull-out load, that point can be selected as Point 2, as shown in Figure 6 . Then, $\delta_{r}$ can be selected in the range between the pull-out displacement at Point 1 and the pull-out displacement at Point 2 . Then, $\tau_{r}$ can be calibrated until the maximum analytical pull-out load fits well with the maximum experimental pull-out load.

\section{Validation of the Analytical Model}

In this section, two experimental pull-out tests were used to validate the credibility of this analytical model.

4.1. Validation with a Pull-Out Test. Bai et al. [58] conducted experimental in situ pull-out tests on rock bolts. Specifically, rock bolts with a radius of $14 \mathrm{~mm}$ were tested, and the embedment length was $3 \mathrm{~m}$. The surrounding rock mass had Young's modulus of $6 \mathrm{GPa}$.

The mechanical properties of the rock bolt and the confining medium used in this analytical model are tabulated in Table 1.

As for the input parameters for the bond-slip model, they can be calibrated from experimental pull-out results, following the methods indicated in Section 3. Then, the 


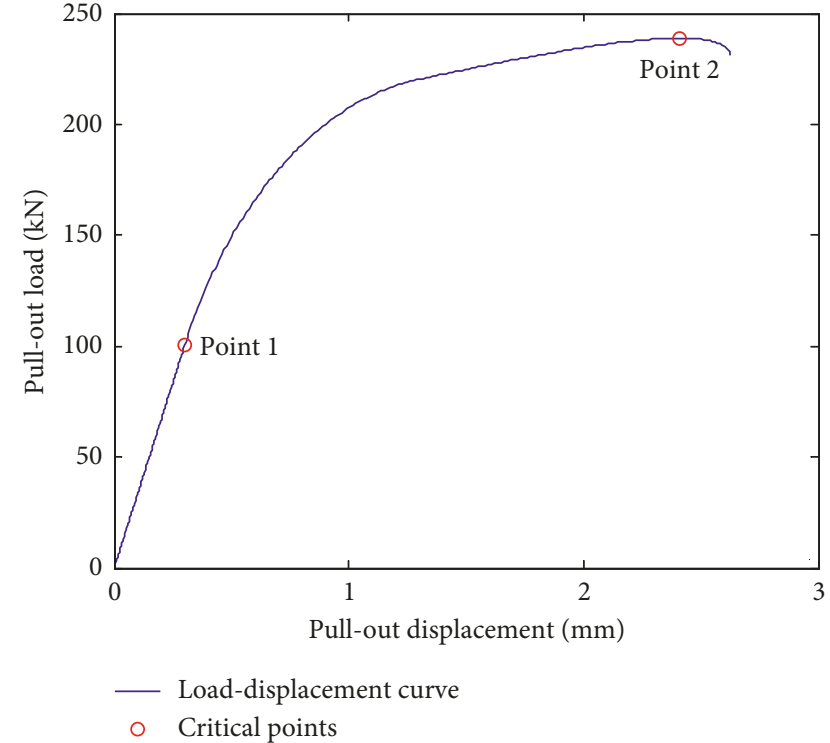

FIGURE 6: Selecting critical points to calibrate the input bond-slip parameters.

parameters tabulated in Table 2 are used in this paper to analytically model the load transfer performance of rock bolts.

A comparison between the experimental result and the analytical result is shown in Figure 7. There is a close match between the experimental result and the analytical result, confirming the credibility of this analytical model.

4.2. Validation with the Other Pull-Out Test. Stillborg [59] conducted a number of pull-out tests in the mine site to study the load transfer performance of cable bolts. Cable bolts with a long embedment length of $10 \mathrm{~m}$ were tested. The cable bolts had a radius of $19 \mathrm{~mm}$ and Young's modulus of $83 \mathrm{GPa}$. The surrounding rock mass had Young's modulus of $57 \mathrm{GPa}$. The mechanical properties of the cable bolt and the confining medium used in this analytical model are tabulated in Table 3.

As for the input parameters for the bond-slip model, they can be calibrated from the experimental pull-out results. In this paper, the parameters tabulated in Table 4 are used to calculate the load-displacement relationship of the cable bolt.

The comparison between the experimental result and the analytical result is shown in Figure 8. It shows that the analytical result agrees well with the experimental result, further confirming that this analytical model can be used to simulate the load transfer performance of rock bolts.

\section{Parametric Study}

A parametric study was conducted to evaluate the input parameters on the load transfer performance of rock bolts. Specifically, the influence of Young's modulus of the confining medium, the shear strength of the bolt/grout interface, and the shear slippage where shear strength of the bolt/grout
TABLE 1: Mechanical properties of the bolt and the confining medium used in this model.

\begin{tabular}{lcccc}
\hline$r_{b}(\mathrm{~mm})$ & $E_{b}(\mathrm{GPa})$ & $L(\mathrm{~m})$ & $E_{m}(\mathrm{GPa})$ & $A_{m}\left(\mathrm{~m}^{2}\right)$ \\
\hline 14 & 51 & 3 & 6 & 1 \\
\hline
\end{tabular}

TABLE 2: Input parameters for the bond-slip model.

\begin{tabular}{lccc}
\hline$\tau_{p}(\mathrm{MPa})$ & $\delta_{p}(\mathrm{~mm})$ & $\tau_{r}(\mathrm{MPa})$ & $\delta_{r}(\mathrm{~mm})$ \\
\hline 2.2 & 3.57 & 1 & 8.91 \\
\hline
\end{tabular}

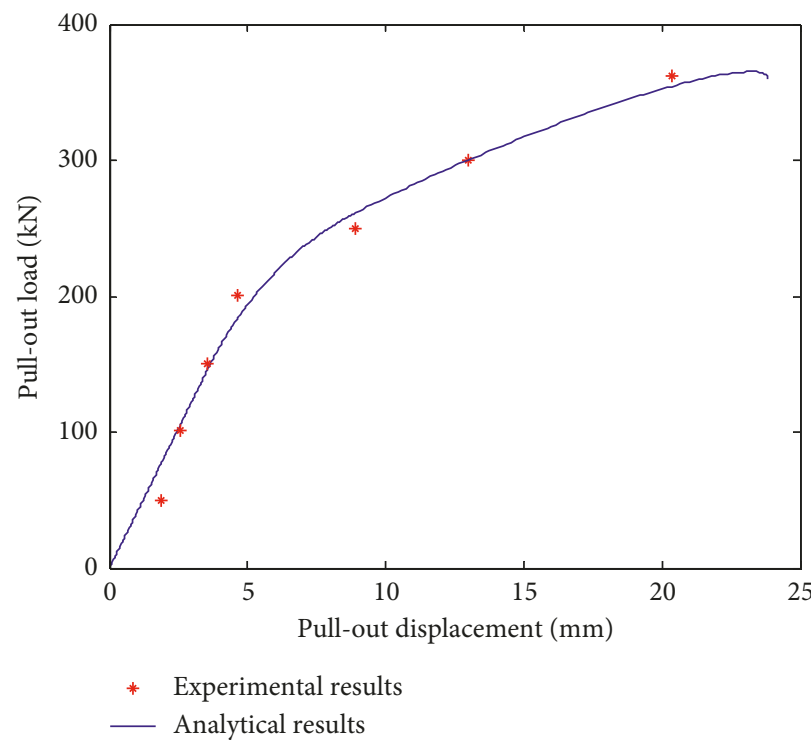

Figure 7: Comparison between the experimental result acquired from Bai et al. [58] and the analytical result.

TABLE 3: Mechanical properties of the cable bolt and the confining medium used in this model.

\begin{tabular}{lcccc}
\hline$r_{b}(\mathrm{~mm})$ & $E_{b}(\mathrm{GPa})$ & $L(\mathrm{~m})$ & $E_{m}(\mathrm{GPa})$ & $A_{m}\left(\mathrm{~m}^{2}\right)$ \\
\hline 19 & 83 & 10 & 57 & 1 \\
\hline
\end{tabular}

interface reaches on the load transfer performance of rock bolts were studied.

5.1. Young's Modulus of the Confining Medium. To study the influence of Young's modulus of the confining medium on the load transfer performance of rock bolts, an analytical rock bolt pull-out scenario was created. A rock bolt with a radius of $10 \mathrm{~mm}$ was tested. Young's modulus of the rock bolt and the embedment length were $196 \mathrm{GPa}$ and $1.5 \mathrm{~m}$. Then, the mechanical properties of the bolt and the confining medium are tabulated in Table 5. As for the input parameters for the bond-slip model, they are tabulated in Table 6.

Young's modulus of the confining medium was changed from $10 \mathrm{MPa}$ to $90 \mathrm{MPa}$, and the load-displacement performance of rock bolts was calculated, as shown in Figure 9. It shows that Young's modulus of the confining medium had 
TABLE 4: Input parameters for the bond-slip model.

\begin{tabular}{lccc}
\hline$\tau_{p}(\mathrm{MPa})$ & $\delta_{p}(\mathrm{~mm})$ & $\tau_{r}(\mathrm{MPa})$ & $\delta_{r}(\mathrm{~mm})$ \\
\hline 1.34 & 10.37 & 0.47 & 35.02 \\
\hline
\end{tabular}

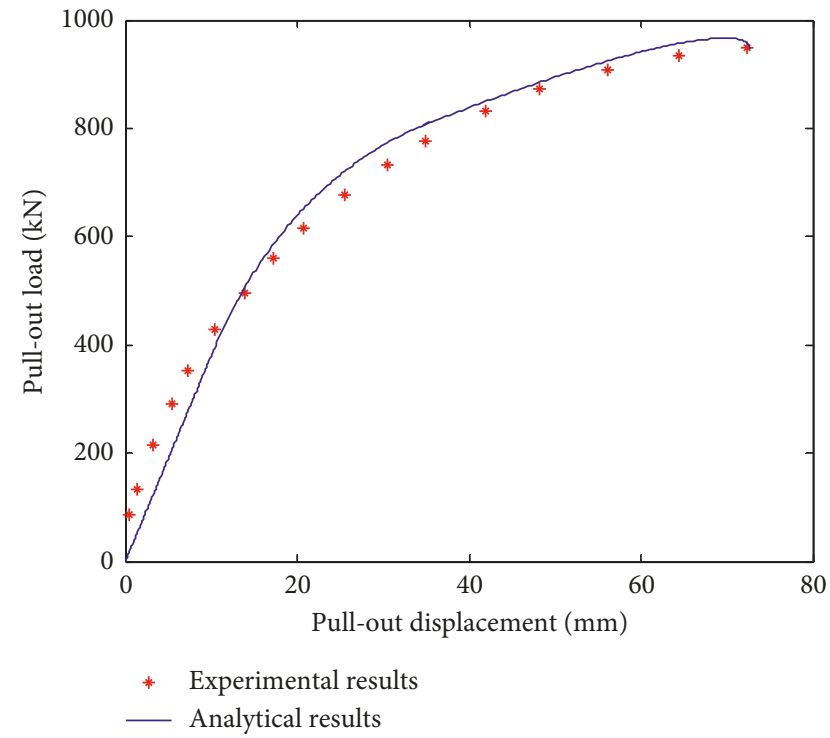

FIGURE 8: Comparison between the experimental result acquired from Stillborg [59] and the analytical result.

an apparent influence on the load transfer performance of rock bolts. The initial stiffness and the peak load of the rock bolting system increased with Young's modulus of the confining medium.

This finding agrees well with previous research. Hyett et al. [60] conducted laboratory and in situ pull-out tests on plain cable bolts. In the laboratory, PVC, aluminium, and steel pipes were used to confine cable bolts. The results showed that the peak load of cable bolts increased with Young's modulus of the confining medium. As for the in situ case, cable bolts were pulled from shale, limestone, and granite. The results showed that when the confining medium changed from shale to granite, the peak load of cable bolts increased apparently.

Figure 9 also shows that with Young's modulus of the confining medium increasing, the increasing rate of the peak load was not constant. To further study the influence of Young's modulus of the confining medium on the peak load, a series of analytical pull-out tests was conducted. The relationship between the rock bolt peak load and Young's modulus of the confining medium was acquired, as shown in Figure 10.

It shows that for this scenario, before Young's modulus of the confining medium increased to $280 \mathrm{MPa}$, the peak load increases rapidly. After that, the peak load is still increasing but with a much lower slope. This indicates that when Young's modulus of the confining medium was higher than a critical limit, it had marginal effect on the peak load of rock bolts.

5.2. Shear Strength of the Bolt/Grout Interface. To study the influence of the shear strength of the bolt/grout interface on
TABLE 5: Mechanical properties of the bolt and the confining medium.

\begin{tabular}{ccccc}
\hline$r_{b}(\mathrm{~mm})$ & $E_{b}(\mathrm{GPa})$ & $L(\mathrm{~m})$ & $E_{m}(\mathrm{MPa})$ & $A_{m}\left(\mathrm{~m}^{2}\right)$ \\
\hline \multirow{3}{*}{10} & & & 10 & \\
& \multirow{2}{*}{196} & 1.5 & 50 & 1 \\
& & & 90 & \\
\hline
\end{tabular}

TABLE 6: Input parameters for the bond-slip model.

\begin{tabular}{lccc}
\hline$\tau_{p}(\mathrm{MPa})$ & $\delta_{p}(\mathrm{~mm})$ & $\tau_{r}(\mathrm{MPa})$ & $\delta_{r}(\mathrm{~mm})$ \\
\hline 2 & 1.5 & 0.8 & 3.5 \\
\hline
\end{tabular}

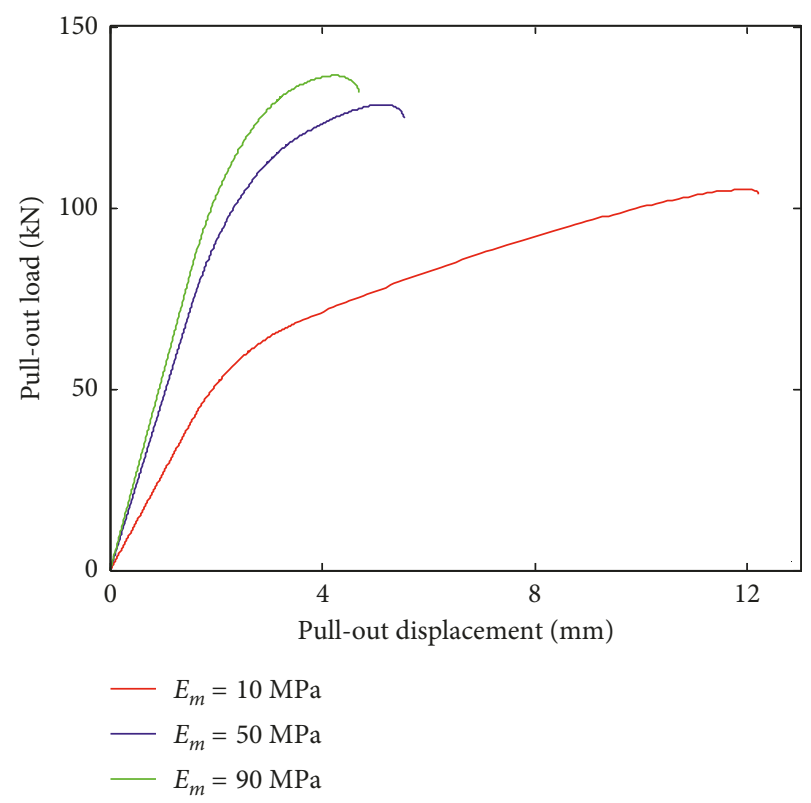

Figure 9: Influence of Young's modulus of the confining medium on the performance of rock bolts.

the load transfer performance of rock bolts, three analytical pull-out tests were conducted. In this case, the shear strength of the bolt/grout interface was varied from $2 \mathrm{MPa}$ to $6 \mathrm{MPa}$. As for the other parameters, they were kept constant.

The mechanical properties for the rock bolt and the confining medium are tabulated in Table 7 . As for the input parameters for the bond-slip model, they are tabulated in Table 8.

A plot of the input bond-slip model is shown in Figure 11. Based on the input bond-slip model, the calculated load transfer performance of rock bolts is shown in Figure 12.

The results show that the shear strength of the bolt/grout interface played a significant role in determining the load transfer performance of rock bolts. Specifically, when the shear strength of the bolt/grout interface was $2 \mathrm{MPa}$, the rock bolt had a maximum pull-out load of $146 \mathrm{kN}$ when the pullout displacement reached $3.1 \mathrm{~mm}$.

Compared with that, when the shear strength of the bolt/ grout interface was $6 \mathrm{MPa}$, the rock bolt had a maximum pullout load of $282 \mathrm{kN}$, increasing by $93.2 \%$. And, the corresponding pull-out displacement reached $4.5 \mathrm{~mm}$. Apparently, 


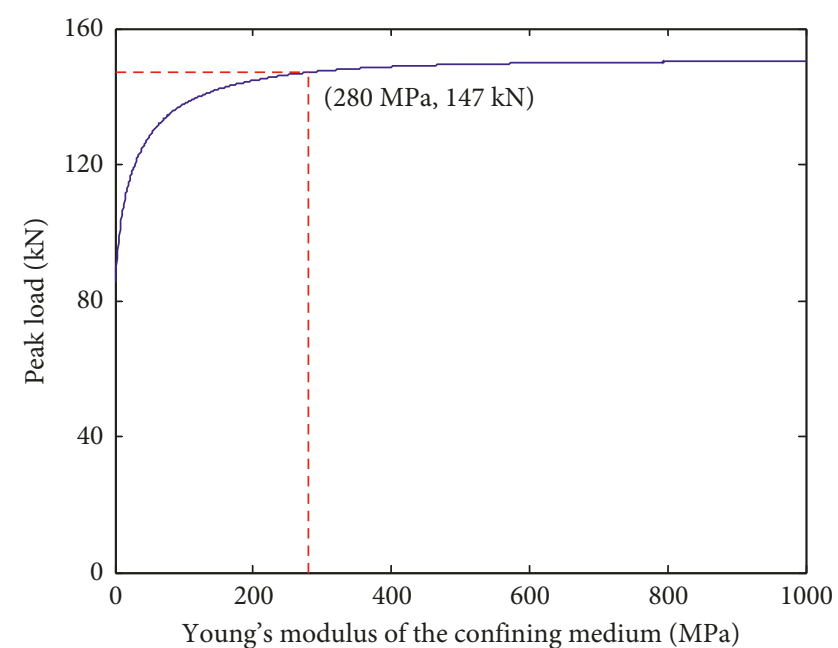

FIGURE 10: Influence of Young's modulus of the confining medium on the peak load of rock bolts.

TABLE 7: Mechanical properties of the bolt and the confining medium.

\begin{tabular}{lcccc}
\hline$r_{b}(\mathrm{~mm})$ & $E_{b}(\mathrm{GPa})$ & $L(\mathrm{~m})$ & $E_{m}(\mathrm{GPa})$ & $A_{m}\left(\mathrm{~m}^{2}\right)$ \\
\hline 10 & 196 & 1.5 & 1 & 1 \\
\hline
\end{tabular}

the larger the shear strength of the bolt/grout interface, the higher the maximum load transfer capacity of rock bolts.

Furthermore, the results show that the shear strength of the bolt/grout interface also had an effect on the initial stiffness of the rock bolting system. With the shear strength of the bolt/grout interface increasing, the initial stiffness of the rock bolting system also increased, as shown in Figure 12.

5.3. Residual Shear Strength of the Bolt/Grout Interface. To study the influence of the residual shear strength of the bolt/grout interface on the load transfer performance of rock bolts, another rock bolt pull-out scenario was created. In this case, the residual shear strength of the bolt/grout interface was varied from $0.5 \mathrm{MPa}$ to $1.5 \mathrm{MPa}$. As for the other parameters, they were kept constant.

The mechanical properties of the rock bolt and the confining medium are tabulated in Table 9. As for the input parameters for the bond-slip model, they are tabulated in Table 10.

A plot of the input bond-slip model is shown in Figure 13. As for the load transfer performance of rock bolts, it is shown in Figure 14.

The results show that the residual shear strength of the bolt/grout interface had no effect on the initial stiffness of the rock bolting system. For example, in this case, when the residual shear strength of the bolt/grout interface increased from $0.5 \mathrm{MPa}$ to $1.5 \mathrm{MPa}$, the initial stiffness of the rock bolting system kept constant.

Nevertheless, the residual shear strength of the bolt/ grout interface had an effect on the maximum load transfer capacity of rock bolts. For example, in this scenario, when
TABLE 8: Input parameters for the bond-slip model.

\begin{tabular}{lccc}
\hline$\tau_{p}(\mathrm{MPa})$ & $\delta_{p}(\mathrm{~mm})$ & $\tau_{r}(\mathrm{MPa})$ & $\delta_{r}(\mathrm{~mm})$ \\
\hline 2 & & & \\
4 & 1.5 & 0.5 & 3.5 \\
6 & & & \\
\hline
\end{tabular}

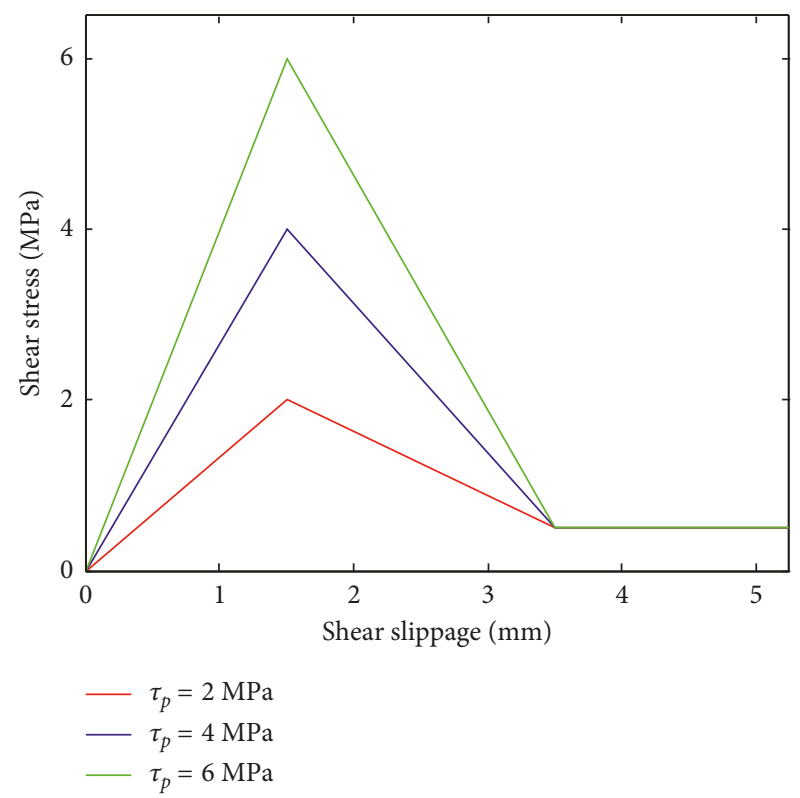

Figure 11: A plot of the input bond-slip model when the shear strength of the bolt/grout interface was different.

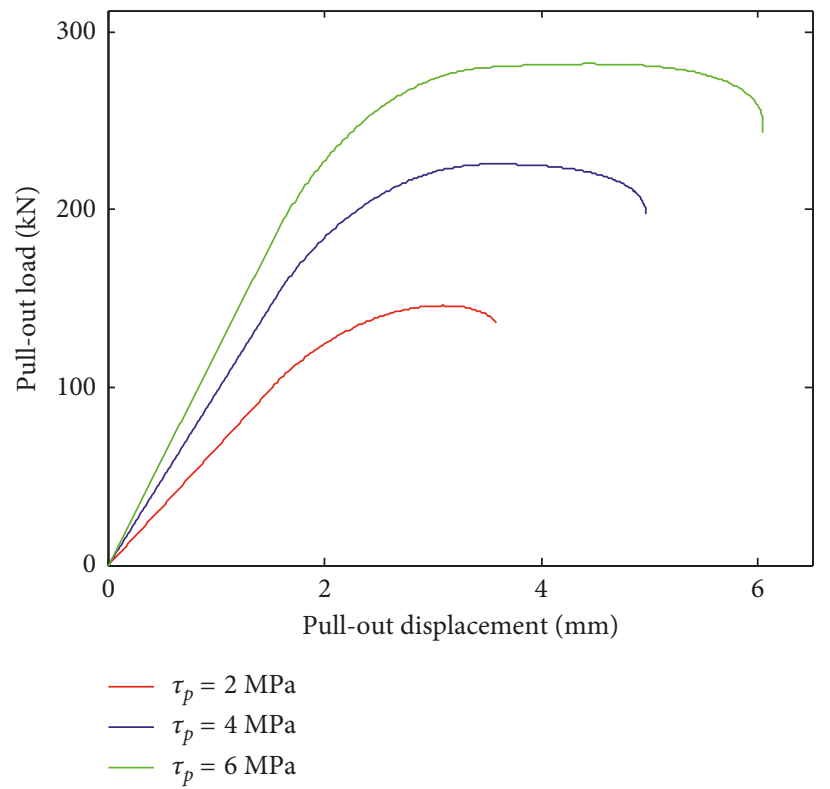

FIGURE 12: Load transfer performance of rock bolts when the shear strength of the bolt/grout interface was different.

the residual shear strength of the bolt/grout interface was $0.5 \mathrm{MPa}$, the maximum pull-out load of rock bolts was $226 \mathrm{kN}$ and the corresponding pull-out displacement was $3.6 \mathrm{~mm}$. Then, when the residual shear strength of the bolt/ 
TABLE 9: Mechanical properties of the bolt and the confining medium.

\begin{tabular}{lcccc}
\hline$r_{b}(\mathrm{~mm})$ & $E_{b}(\mathrm{GPa})$ & $L(\mathrm{~m})$ & $E_{m}(\mathrm{GPa})$ & $A_{m}\left(\mathrm{~m}^{2}\right)$ \\
\hline 10 & 196 & 1.5 & 1 & 1 \\
\hline
\end{tabular}

TABLE 10: Input parameters for the bond-slip model.

\begin{tabular}{lccc}
\hline$\tau_{p}(\mathrm{MPa})$ & $\delta_{p}(\mathrm{~mm})$ & $\tau_{r}(\mathrm{MPa})$ & $\delta_{r}(\mathrm{~mm})$ \\
\hline \multirow{3}{*}{4} & & 0.5 & \\
& 1.5 & 1 & 3.5 \\
& & 1.5 & \\
\hline
\end{tabular}

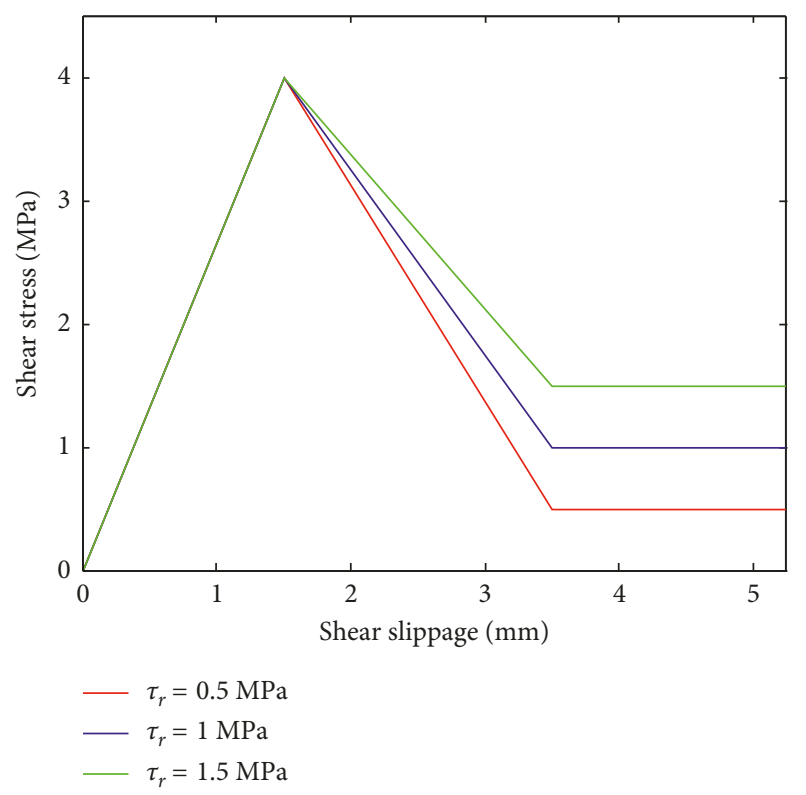

FIGURE 13: A plot of the input bond-slip model when the residual shear strength of the bolt/grout interface was different.

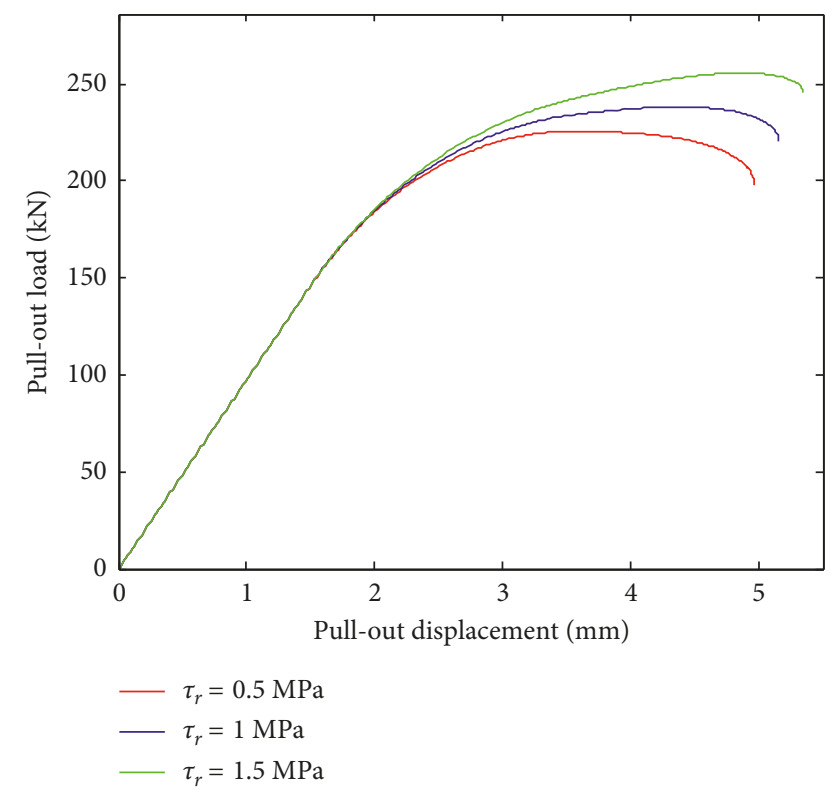

FIGURE 14: Load transfer performance of rock bolts when the residual shear strength of the bolt/grout interface was different. grout interface increased to $1.5 \mathrm{MPa}$, the maximum pull-out load of rock bolts increased to $256 \mathrm{kN}$, increasing by $13.3 \%$. And, the corresponding pull-out displacement was $4.9 \mathrm{~mm}$. Apparently, increasing the residual shear strength of the bolt/grout interface was beneficial for improving the maximum load transfer capacity of rock bolts.

Additionally, compared with the shear strength of the bolt/grout interface, increasing the residual shear strength of the bolt/grout interface had less apparent effect in improving the maximum load transfer capacity of rock bolts. For example, in the aforementioned analysis, when the residual shear strength of the bolt/grout interface increased by $200 \%$, the maximum pull-out load of rock bolts only increased by $13.3 \%$. However, when the shear strength of the bolt/grout interface increased by $200 \%$, the maximum pull-out load of rock bolts largely increased by $93.2 \%$. Therefore, the shear strength of the bolt/grout interface had more significant effect in deciding the maximum load transfer capacity of rock bolts.

The contribution of this paper is that it concentrated on fully grouted rock bolts with long embedment length grouted in the surrounding confining medium. Specifically, based on the previous work [38, 47], this paper acquired the specific analytical solution for this scenario. Furthermore, based on the acquired specific analytical solution, it further studied the influence of Young's modulus of the confining medium on the load transfer performance of rock bolts. It revealed that although the peak load of rock bolts increased with Young's modulus of the confining medium, there was a critical limit. Once Young's modulus of the confining medium was beyond that critical limit, it had marginal effect on the peak load of rock bolts.

\section{Conclusions}

A trilinear model was adopted to depict the bond-slip behaviour of the bolt/grout interface. It was assumed that the shear stress of the bolt/grout interface increased linearly to the shear strength of the bolt/grout interface with the shear slippage. Then, the shear stress decreased linearly to the residual shear strength of the bolt/grout interface with the shear slippage. After that, the shear stress kept constant.

The pull-out stages of rock bolts were analysed. During the pull-out process, the bolt/grout interface underwent elastic, elastic-softening, elastic-softening-debonding, softening-debonding, and debonding stages.

Experimental pull-out tests were used to validate the credibility of this analytical model. The results show that there was a good correlation between experimental and analytical results.

A parametric study was conducted to evaluate Young's modulus of the confining medium, the shear strength of the bolt/grout interface, and the residual shear strength of the bolt/grout interface on the load transfer performance of rock bolts. The results show that increasing Young's modulus of the confining medium was beneficial for improving the load transfer performance of rock bolts. However, once Young's modulus of the confining medium was beyond a critical limit, it had a marginal effect on the peak load of rock bolts. 
Additionally, increasing the shear strength of the bolt/grout interface and the residual shear strength of the bolt/grout interface led to rising of the peak load of rock bolts. However, compared with the residual shear strength of the bolt/grout interface, increasing the shear strength of the bolt/grout interface had more apparent effect in improving the load transfer capacity of rock bolts.

\section{Nomenclature}

$\begin{array}{ll}A_{m}: & \text { The cross-sectional area of the confining } \\ & \text { medium, } \mathrm{m}^{2} \\ a_{d}: & \text { The debonding length, } \mathrm{m} \\ a_{s}: & \text { The softening length, } \mathrm{m} \\ a_{s 1}: & \text { The softening length when the elastic-softening }\end{array}$

$a_{s 2}: \quad$ stage ends, $m$

debonding stage ends, $m$

$D_{b}$ : The diameter of the rock bolt, $m$

$E_{b}$ : $\quad$ Young's modulus of the rock bolt, $\mathrm{Pa}$

$E_{m}$ : Young's modulus of the confining medium, $\mathrm{Pa}$

F: $\quad$ The pull-out load, N

$F_{\text {sof }}$ The pull-out load when the bolt/grout interface starts softening, $\mathrm{N}$

$F_{0}$ : The pull-out load at the start of the debonding stage, $\mathrm{N}$

L: $\quad$ Embedment length, $\mathrm{m}$

$r_{b}: \quad$ The rock bolt radius, $\mathrm{m}$

$u_{b}$ : The pull-out displacement of the rock bolt, $\mathrm{m}$

$u_{b}(x): \quad$ The pull-out displacement of the rock bolt at the position of $x, \mathrm{~m}$

$u_{m}(x)$ : The axial displacement of the confining medium at the position of $x, \mathrm{~m}$

$\delta_{p}$ : The shear slippage of the bolt/grout interface when the shear strength of the bolt/grout interface reaches, $\mathrm{m}$

$\delta_{r}$ : The shear slippage of the bolt/grout interface when the residual shear strength of the bolt/ grout interface reaches, $\mathrm{m}$

$\delta(x): \quad$ The shear slippage of the bolt/grout interface at the position of $x, \mathrm{~m}$

$u_{b 0}$ : The pull-out displacement of the rock bolt at the start of the debonding stage, $\mathrm{m}$

$\lambda, \lambda_{1}$, and Coefficients

$\lambda_{2}$ :

$\sigma_{b}(x)$ : The axial stress of the rock bolt at the position of $x, \mathrm{~Pa}$

$\sigma_{m}(x): \quad$ The axial stress applied on the confining medium at the position of $x, \mathrm{~Pa}$

$\tau_{p}: \quad$ The shear strength of the bolt/grout interface, $\mathrm{Pa}$

$\tau_{r}$ : The residual shear strength of the bolt/grout interface, $\mathrm{Pa}$

$\tau(x)$ : The shear stress of the bolt/grout interface at the position of $x, \mathrm{~Pa}$.

\section{Data Availability}

The data used to support the findings of this study are included in the article.

\section{Conflicts of Interest}

The authors declare that there are no conflicts of interest to report.

\section{Acknowledgments}

This study was supported by the National Key R\&D Program of China (2018YFC0604703), the National Natural Science Foundation of China (51574243), the Yue Qi Distinguished Scholar Project (800015Z1138), the China University of Mining and Technology, Beijing, and the Fundamental Research Funds for the Central Universities (800015J6).

\section{References}

[1] N. Vlachopoulos, D. Cruz, and B. Forbes, "Utilizing a novel fiber optic technology to capture the axial responses of fully grouted rock bolts," Journal of Rock Mechanics and Geotechnical Engineering, vol. 10, no. 2, pp. 222-235, 2018.

[2] B. Meng, H. Jing, S. Yang, Y. Wang, and B. Li, "Experimental study on the shear behavior of bolted concrete blocks with oblique shear test," Advances in Civil Engineering, vol. 2018, Article ID 7281218, 8 pages, 2018.

[3] H. Wang, Q. Wang, F. Wang et al., "Mechanical effect analysis of bolts in roadway under different anchoring lengths and its application," Journal of China Coal Society, vol. 40, no. 3, pp. 509-515, 2015.

[4] Y. Yokota, Z. Zhao, J. Shang et al., "Effect of bolt configuration on the interface behaviour between a rock bolt and bond material: a comprehensive DDA investigation," Computers and Geotechnics, vol. 105, pp. 116-128, 2019.

[5] Z. Zhang, W. Wang, S. Li et al., "An innovative approach for gob-side entry retaining with thick and hard roof: a case study," Technical Gazette, vol. 25, no. 4, pp. 1028-1036, 2018.

[6] Z. Zhang, X. Yu, H. Wu, and M. Deng, "Stability control for gob-side entry retaining with supercritical retained entry width in thick coal seam longwall mining," Energies, vol. 12, no. 7, p. 1375, 2019.

[7] C. R. Windsor, "Rock reinforcement systems," International Journal of Rock Mechanics and Mining Sciences, vol. 34, no. 6, pp. 919-951, 1997.

[8] Y. Wang, Y. Gao, E. Wang, M. He, and J. Yang, "Roof deformation characteristics and preventive techniques using a novel non-pillar mining method of gob-side entry retaining by roof cutting," Energies, vol. 11, no. 3, p. 627, 2018.

[9] D. Hou and X. Yang, "Physical modeling of displacement and failure monitoring of underground roadway in horizontal strata," Advances in Civil Engineering, vol. 2018, Article ID 2934302, 11 pages, 2018.

[10] A. G. Thompson, E. Villaescusa, and C. R. Windsor, "Ground support terminology and classification: an update," Geotechnical and Geological Engineering, vol. 30, no. 3, pp. 553580, 2012.

[11] S. Ma, Z. Zhao, W. Nie, and Y. Gui, "A numerical model of fully grouted bolts considering the tri-linear shear bond-slip model," Tunnelling and Underground Space Technology, vol. 54, pp. 73-80, 2016.

[12] J. Chen, P. C. Hagan, and S. Saydam, "Sample diameter effect on bonding capacity of fully grouted cable bolts," Tunnelling and Underground Space Technology, vol. 68, pp. 238-243, 2017. 
[13] J. Chen, S. Saydam, and P. C. Hagan, "An analytical model of the load transfer behavior of fully grouted cable bolts," Construction and Building Materials, vol. 101, pp. 1006-1015, 2015.

[14] A. Mirzaghorbanali, H. Rasekh, N. Aziz, G. Yang, S. Khaleghparast, and J. Nemcik, "Shear strength properties of cable bolts using a new double shear instrument, experimental study, and numerical simulation," Tunnelling and Underground Space Technology, vol. 70, pp. 240-253, 2017.

[15] M. L. Jeremic and G. J. P. Delaire, "Failure mechanics of cable bolt systems," CIM Bulletin, vol. 76, no. 856, pp. 66-71, 1983.

[16] D. J. Hutchinson and M. S. Diederichs, Cablebolting in Underground Mines, BiTech Publishers Ltd., Richmond, VA, USA, 1996.

[17] X. Feng, N. Zhang, S. Yang, and F. He, "Mechanical response of fully bonded bolts under cyclic load," International Journal of Rock Mechanics and Mining Sciences, vol. 109, pp. 138-154, 2018.

[18] H. Jalalifar, A New Approach in Determining the Load Transfer Mechanism in Fully Grouted Bolts, University of Wollongong, Wollongong, Australia, 2006.

[19] J. Chen, P. C. Hagan, and S. Saydam, "Load transfer behavior of fully grouted cable bolts reinforced in weak rocks under tensile loading conditions," Geotechnical Testing Journal, vol. 39, no. 2, Article ID 20150096, 2016.

[20] J. Chai, Q. Liu, J. Liu, G. Zhang, D. Zhang, and F. Qiu, "Assessing the difference in measuring bolt stress: a comparison of two optical fiber sensing techniques," Journal of Sensors, vol. 2018, Article ID 7582605, 11 pages, 2018.

[21] P. G. Gambarova, "On aggregate interlock mechanism in reinforced concrete plates with extensive cracking," IABSE Reports of the Working Commissions, vol. 34, pp. 99-120, 1981.

[22] S. Ma, N. Aziz, J. Nemcik, and A. Mirzaghorbanali, "The effects of installation procedure on bond characteristics of fully grouted rock bolts," Geotechnical Testing Journal, vol. 40, no. 5, Article ID 20160239, 2017.

[23] T. Wu, C. Cao, J. Han, and T. Ren, "Effect of bolt rib spacing on load transfer mechanism," International Journal of Mining Science and Technology, vol. 27, no. 3, pp. 431-434, 2017.

[24] C. C. Li, G. Kristjansson, and A. H. Høien, "Critical embedment length and bond strength of fully encapsulated rebar rockbolts," Tunnelling and Underground Space Technology, vol. 59, pp. 16-23, 2016.

[25] A. Mortazavi, "Anchorage and shear strength properties for composite tendons used in earthwork support systems," Construction and Building Materials, vol. 21, no. 1, pp. 109117, 2007.

[26] J. M. Hawkes and R. H. Evans, "Bond stresses in reinforced concrete columns and beams," Structural Engineering, vol. 29, pp. 323-327, 1951.

[27] I. W. Farmer, "Stress distribution along a resin grouted rock anchor," International Journal for Numerical and Analytical Methods in Geomechanics, vol. 12, no. 11, pp. 347-351, 1975.

[28] O. Aydan, Y. Ichikawa, and K. Kawamoto, "Load bearing capacity and stress distributions in/along rockbolts with inelastic behaviour of interfaces," in Proceedings of the Fifth International Conference on Numerical Methods in Geomechanics, pp. 1281-1292, Nagoya, Japan, April 1985.

[29] H. Rajaie, Experimental and Numerical Investigations of Cable Bolt Support Systems, McGill University, Montreal, Canada, 1990.

[30] S. Yazici and P. K. Kaiser, "Bond strength of grouted cable bolts," International Journal of Rock Mechanics and Mining Sciences \& Geomechanics Abstracts, vol. 29, no. 3, pp. 279292, 1992.
[31] P. K. Kaiser, S. Yazici, and J. Nosé, "Effect of stress change on the bond strength of fully grouted cables," International Journal of Rock Mechanics and Mining Sciences \& Geomechanics Abstracts, vol. 29, no. 3, pp. 293-306, 1992.

[32] A. J. Hyett, W. F. Bawden, G. R. Macsporran, and M. Moosavi, "A constitutive law for bond failure of fully-grouted cable bolts using a modified hoek cell," International Journal for Numerical and Analytical Methods in Geomechanics, vol. 32, no. 1, pp. 11-36, 1995.

[33] A. J. Hyett, M. Moosavi, and W. F. Bawden, "Load distribution along fully grouted bolts, with emphasis on cable bolt reinforcement," International Journal for Numerical and Analytical Methods in Geomechanics, vol. 20, no. 7, pp. 517544, 1996.

[34] M. Moosavi, "A comprehensive comparison between bond failure mechanism in rock bolts and cable bolts," in Proceedings of the Congress of the International Society for Rock Mechanics, pp. 1463-1466, Montreal, Canada, November 1999.

[35] C. Li and B. Stillborg, "Analytical models for rock bolts," International Journal of Rock Mechanics and Mining Sciences, vol. 36, no. 8, pp. 1013-1029, 1999.

[36] Y. Cai, T. Esaki, and Y. Jiang, "An analytical model to predict axial load in grouted rock bolt for soft rock tunnelling," Tunnelling and Underground Space Technology, vol. 19, no. 6, pp. 607-618, 2004.

[37] S.-J. Xiao and C.-F. Chen, "Mechanical mechanism analysis of tension type anchor based on shear displacement method," Journal of Central South University of Technology, vol. 15, no. 1, pp. 106-111, 2008.

[38] F. F. Ren, Z. J. Yang, J. F. Chen, and W. W. Chen, "An analytical analysis of the full-range behaviour of grouted rockbolts based on a tri-linear bond-slip model," Construction and Building Materials, vol. 24, no. 3, pp. 361-370, 2010.

[39] L. Blanco Martín, M. Tijani, and F. Hadj-Hassen, "A new analytical solution to the mechanical behaviour of fully grouted rockbolts subjected to pull-out tests," Construction and Building Materials, vol. 25, no. 2, pp. 749-755, 2011.

[40] H. Jalalifar, "An analytical solution to predict axial load along fully grouted bolts in an elasto-plastic rock mass," The Journal of the Southern Afrcan Institute of Mining and Metallurgy, vol. 111, pp. 809-814, 2011.

[41] C. Cao, J. Nemcik, N. Aziz, and T. Ren, "Analytical study of steel bolt profile and its influence on bolt load transfer," International Journal of Rock Mechanics and Mining Sciences, vol. 60, pp. 188-195, 2013.

[42] S. Ma, J. Nemcik, and N. Aziz, "An analytical model of fully grouted rock bolts subjected to tensile load," Construction and Building Materials, vol. 49, pp. 519-526, 2013.

[43] S. Ma, J. Nemcik, N. Aziz, and Z. Zhang, "Analytical model for rock bolts reaching free end slip," Construction and Building Materials, vol. 57, pp. 30-37, 2014.

[44] D. Li, H. Masoumi, S. Saydam, and P. C. Hagan, "A constitutive model for load-displacement performance of modified cable bolts," Tunnelling and Underground Space Technology, vol. 68, pp. 95-105, 2017.

[45] D. D. Faulkner and S. S. Peng, "The development and application of polyurethane injectable cable bolts," in Proceedings of the International Conference on Ground Control in Mining, ICGCM, pp. 1-5, Morgantown, USA, August 2012.

[46] B. Benmokrane, A. Chennouf, and H. S. Mitri, "Laboratory evaluation of cement-based grouts and grouted rock anchors," International Journal of Rock Mechanics and Mining Sciences \& Geomechanics Abstracts, vol. 32, no. 7, pp. 633-642, 1995. 
[47] J. Vaculik, A. B. Sturm, P. Visintin, and M. C. Griffith, "Modelling FRP-to-substrate joints using the bilinear bondslip rule with allowance for friction-full-range analytical solutions for long and short bonded lengths," International Journal of Solids and Structures, vol. 135, pp. 245-260, 2018.

[48] A. Teymen and A. Kilıç, "Effect of grout strength on the stress distribution (tensile) of fully-grouted rockbolts," Tunnelling and Underground Space Technology, vol. 77, pp. 280-287, 2018.

[49] S. Ding, H. Jing, K. Chen, G. A. Xu, and B. Meng, "Stress evolution and support mechanism of a bolt anchored in a rock mass with a weak interlayer," International Journal of Mining Science and Technology, vol. 27, no. 3, pp. 573-580, 2017.

[50] M. Bastami, K. Shahriar, and M. Ghadimi, "Verification of the analytical model for fully grouted rock bolts based on pull-out test (case study: Tabas coal mine)," Procedia Engineering, vol. 191, pp. 1068-1074, 2017.

[51] C. Cao, N. Jan, T. Ren, and A. Naj, "A study of rock bolting failure modes," International Journal of Mining Science and Technology, vol. 23, no. 1, pp. 79-88, 2013.

[52] J. Zhang and B. Tang, "Hyperbolic function model to analyze load transfer mechanism on bolts," Chinese Journal of Geotechnical Engineering, vol. 24, no. 2, pp. 188-192, 2002.

[53] H. Yuan, J. G. Teng, R. Seracino, Z. S. Wu, and J. Yao, "Fullrange behavior of FRP-to-concrete bonded joints," Engineering Structures, vol. 26, no. 5, pp. 553-565, 2004.

[54] Z. Tao and J. Chen, "Behaviour of rock bolting as tunnelling support," in Proceedings of the International Symposium on Rock Bolting, O. Stephansson, Ed., pp. 87-92, A. A. Balkema, Abisko, Sweden, 1983.

[55] Y. Cai, T. Esaki, and Y. Jiang, "A rock bolt and rock mass interaction model," International Journal of Rock Mechanics and Mining Sciences, vol. 41, no. 7, pp. 1055-1067, 2004.

[56] L. Blanco Martín, M. Tijani, F. Hadj-Hassen, and A. Noiret, "Assessment of the bolt-grout interface behaviour of fully grouted rockbolts from laboratory experiments under axial loads," International Journal of Rock Mechanics and Mining Sciences, vol. 63, pp. 50-61, 2013.

[57] Z. Wu, S. Yang, J. Zheng, and X. Hu, "Analytical solution for the pull-out response of FRP rods embedded in steel tubes filled with cement grout," Materials and Structures, vol. 43, no. 5, pp. 597-609, 2010.

[58] X. Bai, M. Zhang, and N. Yan, "Field contrast test and mechanism analysis on anchorage performance of antifloating anchors with two different materials," China Civil Engineering Journal, vol. 48, no. 8, pp. 38-59, 2015.

[59] B. Stillborg, Experimental Investigation of Steel Cables for Rock Reinforcement in Hard Rock, Luleå University, Luleå, Sweden, 1984.

[60] A. J. Hyett, W. F. Bawden, and R. D. Reichert, "The effect of rock mass confinement on the bond strength of fully grouted cable bolts," International Journal of Rock Mechanics and Mining Sciences \& Geomechanics Abstracts, vol. 29, no. 5, pp. 503-524, 1992. 


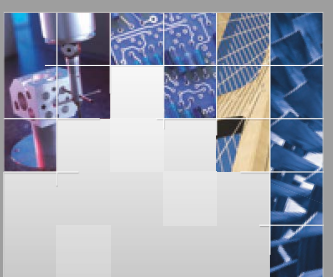

\section{Enfincering}
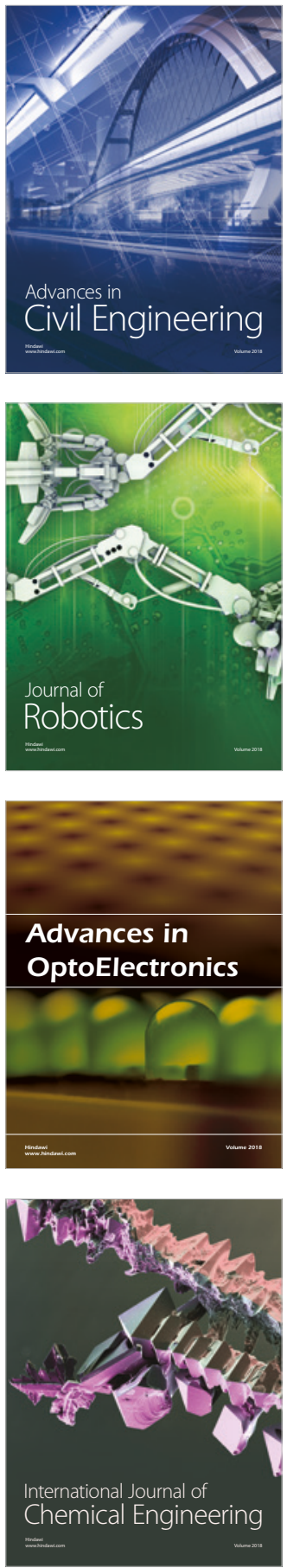

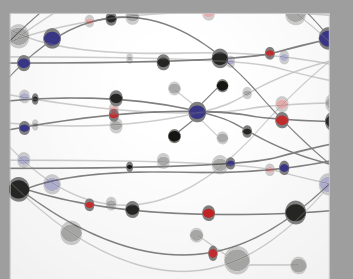

\section{Rotating \\ Machinery}

The Scientific World Journal

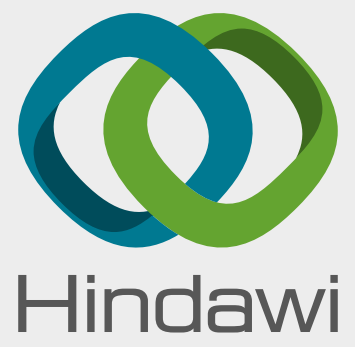

Submit your manuscripts at

www.hindawi.com
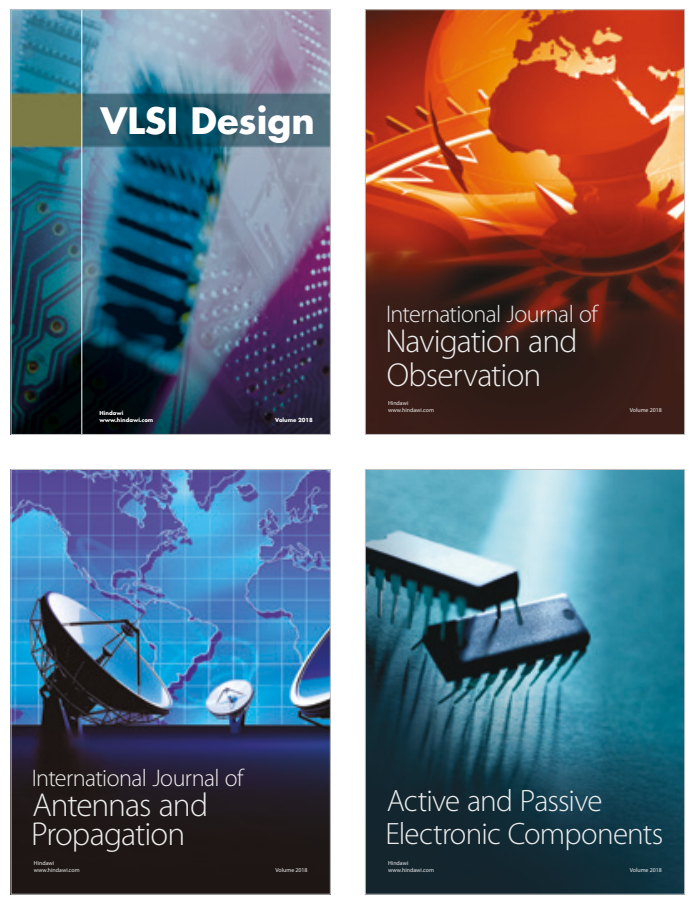
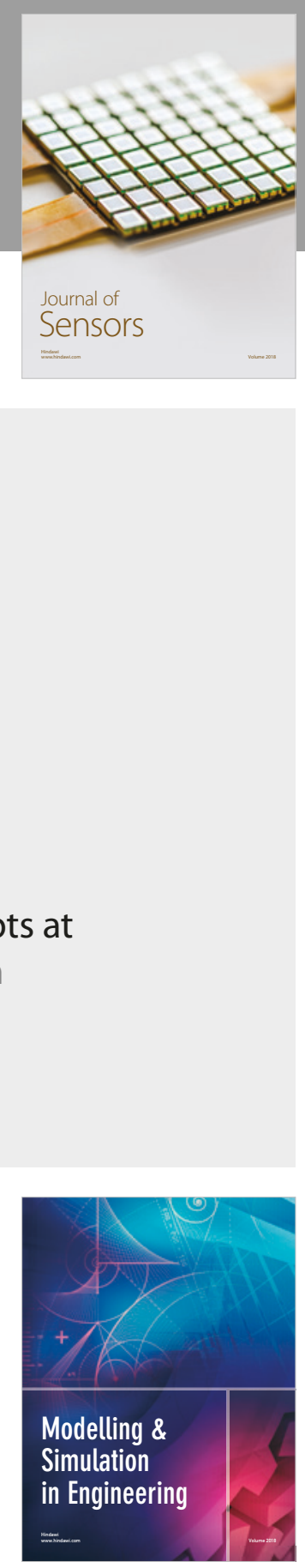

\section{Advances \\ Multimedia}
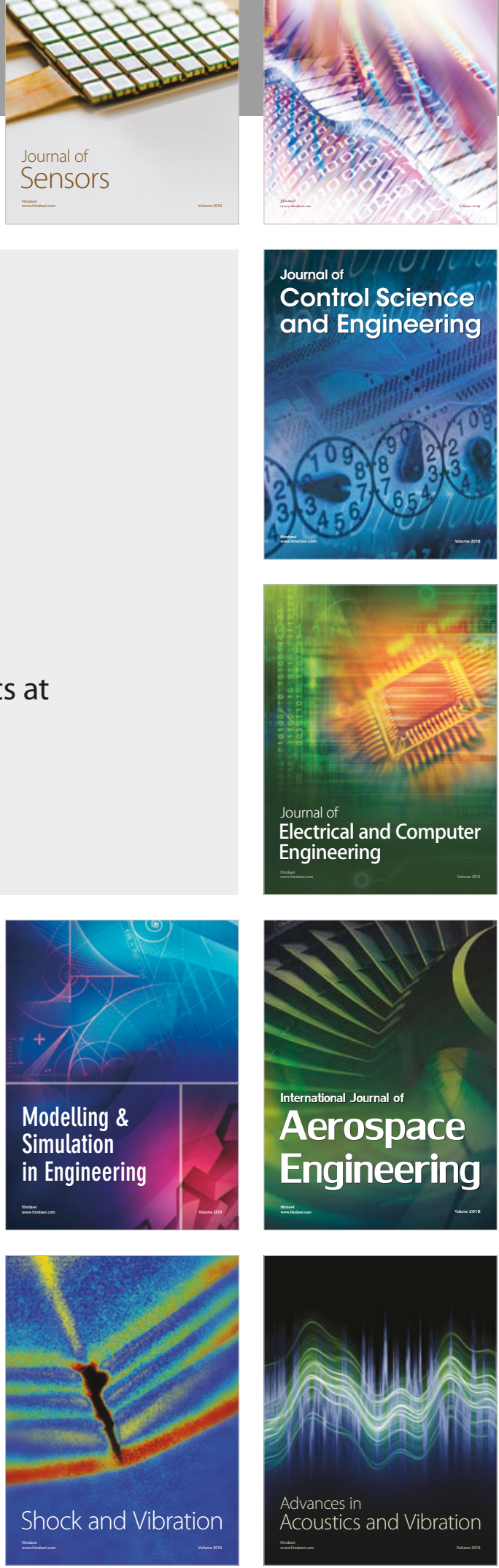